
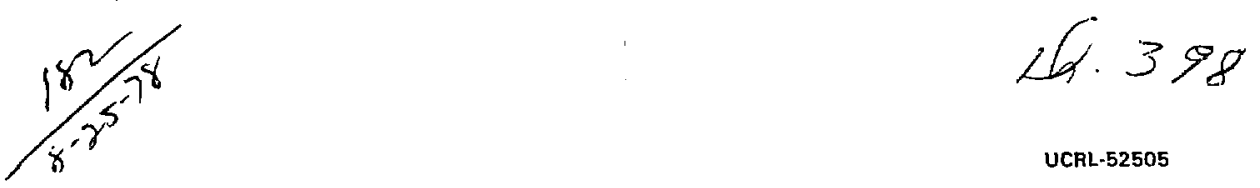

\title{
AN ANALYSIS OF THE POWDER DIFFRACTION FILE
}

\author{
R. L. Snyder, A. C. Johnson, E. Kahara, \\ G. S. Smith, and M. C. Nichols
}

\section{MASTER}

June 22, 1978

Work performed uncer the auspices of the U.S. Department of

Energy by the UCLLL under contract number W-7405-ENG-4B.
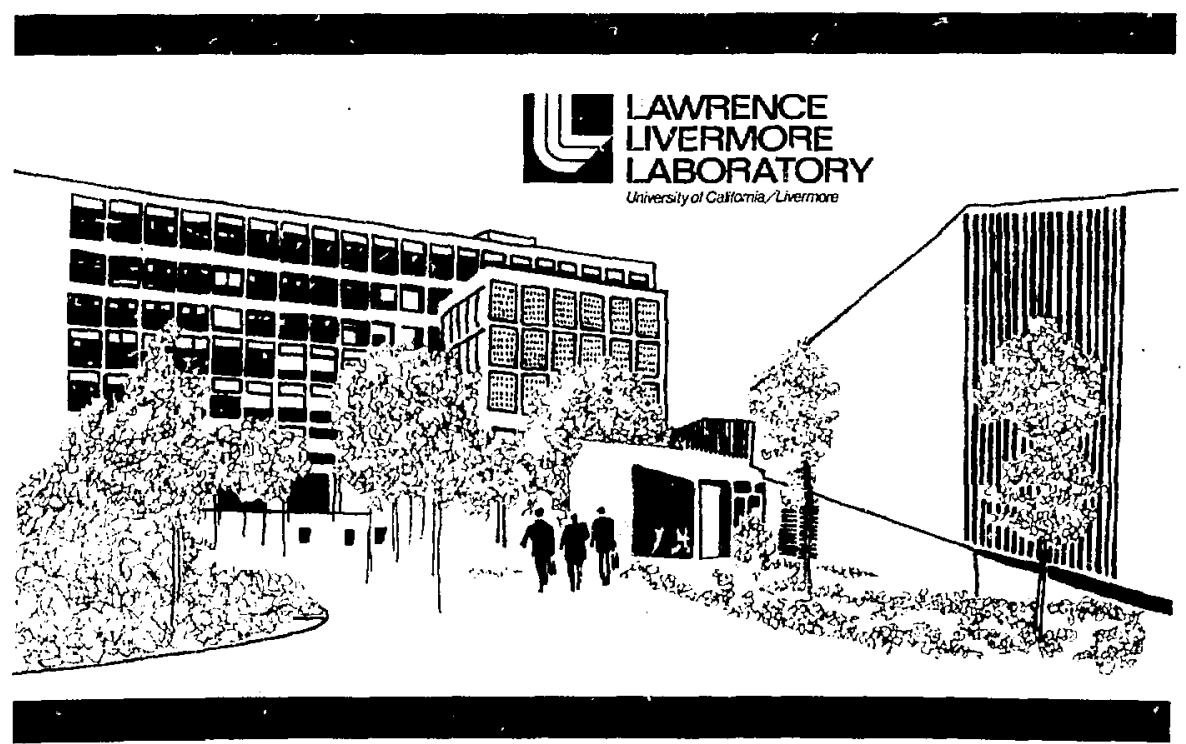


\title{
㢟 \\ LAWRENCE IJVERMORE IABORATOFY \\ University of Calfomia/Livermore, Calitornia, 94550
}

UCRL-52505

\section{AN ANALYSIS OF THE POWDER DIFFRACTION FILE}

\author{
By \\ R. L. Snyder*, \\ And \\ M. C. Nichols** \\ MS. date: June 22, 1978

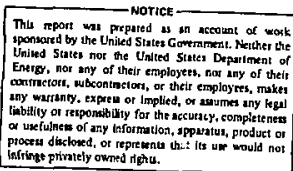

Q. C. Johnson, E. Kahara, G. S. Smith

*With NYS College of Ceramics, Alfred Uni,er sity, Alfred, N.Y. 14802

**With Sandia Laboratory, Livermore, CA $94: 30$ 


\title{
AN ANALYSIS OF THE POWDER DIFFRACTION FILE
}

\begin{abstract}
The International Centre for Powder Diffraction Data has compiled an extensive powder diffraction database available on magnetic tape. We evaluated the database to determine the type and quality of the information it contains, including an analysis of d-I pairs per pattern, symmetry, quality marks, $Q$ values, and intensities for subfiles of known crystal class. In addition, we evaluated nine functions to assess pattern quality for cubic and triclinic data. We present here a minimum amount of data analysis, but rather concentrate on the distribution and statistics. We also describe how these data were obtained.
\end{abstract}

\section{INTRODUCTION}

The purpose of this study is to establish the characteristics and quality of the Powder Diffraction File (PDF) as compiled and distributed on computer tape by the JCPDS (International Centre for Powder Diffraction Data). I' Although the PDF has previously been studied, ${ }^{2,3}$ we have investigated several new search and identification procedures.

For our -study we created or used three different powder fraction databases. All computer analyses were conducted on Control Data Corporation 7600 computers at Lawrence Livermore Laboratory. In addition, all of the figures were generated using the general plotting program CHARTIT. ${ }^{4}$ The plots presented here in black and white were originally generated in color on a DICOMED D48 photographic plotting device. All programs referred to in this report were written in FORTRAN IV.

\section{ANALYSIS OF THE COMPLETE POWDER DIFFRACTION DATABASE}

We used sets 1 through 26 of the PDF as received on magnetic tape from the JCPDS to analyze the number and some characteristics of the patterns. The computer program that prepared this data is called DISTAT. Tables 1 and 2 show the breakdown of totals by set number for inorganic and organic patterns, respectively. Deleted patterns refer to those replaced by JCPDS editors in a later set. The old pattern is often left on the tape but marked as deleted.

The crystal-class indicator has been placed on only $16.2 \%$ of the file patterns on the magnetic tape. Patterns marked with an asterisk have been judged by the editors to be of high quality; patterns marked with a "c" are calculated from structural data; patterns murked with an "I" are indexed. The final three columns of Tables 1 and 2 give the number of patterns that have quality marks but no symmetry indication. To obtain the number of patterns with both a quality mark and symmetry indicator, subtract the proper columns (i.e. Col. 10-Col. 13). Table 3 gives a further breakdown of symmetry vs quality mark for the inorganic file only. This table contains the actual symbols found on the tape, indicating not only crystal class, but Bravais lattice type. The symbols have the following meaning:

$$
\begin{aligned}
& \text { C - Primitive cubic } \\
& \text { F - Face-centered cubic } \\
& \text { B - Body-centered cubic } \\
& \text { T - Primitive tetragonal } \\
& \text { U - Base-centered tetragonal } \\
& \text { R - Rhombohedral } \\
& \text { H - Hexagonal } \\
& \text { O - Primitive orthorhombic } \\
& \text { P - Body-centered orthorhombic }
\end{aligned}
$$


Table 1. Statistics on the inorganic powder difraction data base, sets 1-26.

\begin{tabular}{|c|c|c|c|c|c|c|c|c|c|c|c|c|c|c|}
\hline SET & TOT & DEL & CUB & TET & HEX & ORT & MON & TRI & AST & CAL & IND & NS ${ }^{*}$ & NSC & NSI \\
\hline 1 & 358 & 59 & 0 & 0 & 0 & 0 & 0 & 0 & 0 & 0 & 1 & 0 & 0 & 0 \\
\hline 2 & 362 & 43 & 0 & 0 & 1 & 0 & 0 & 0 & 0 & 0 & 15 & 0 & 0 & 15 \\
\hline 3 & 284 & 44 & 0 & 0 & 1 & 0 & 0 & 0 & 0 & 0 & 12 & 0 & 0 & 12 \\
\hline 4 & 228 & 23 & 0 & 0 & 0 & 0 & ) & 0 & 37 & 0 & 21 & 37 & 0 & 21 \\
\hline 5 & 212 & 22 & 0 & 0 & 1 & I & 2 & 0 & 59 & 0 & 13 & 59 & 0 & 13 \\
\hline 6 & 448 & 32 & 65 & 33 & 57 & 17 & 4 & 11 & 150 & 0 & 30 & 119 & 0 & 30 \\
\hline 7 & 331 & 17 & 42 & 26 & 32 & 15 & 0 & 0 & 128 & 0 & 21 & 122 & 0 & 21 \\
\hline 8 & 356 & 26 & 36 & 15 & 24 & 3 & 1 & 0 & 101 & 0 & 58 & 95 & 0 & 55 \\
\hline 9 & 400 & 17 & 30 & 21 & 30 & 16 & 3 & 0 & 128 & 0 & 51 & 121 & 0 & 48 \\
\hline 10 & 385 & 23 & 38 & 8 & 20 & 9 & 0 & o & 77 & 0 & 41 & 72 & 0 & 38 \\
\hline 11 & 533 & 43 & 28 & 9 & 11 & 10 & 2 & $\mathbf{0}$ & 142 & 1 & 72 & 131 & 1 & 69 \\
\hline 12 & 661 & 35 & 41 & 13 & 37 & 14 & 2 & 0 & 112 & 0 & 90 & 105 & 0 & 86 \\
\hline 13 & 484 & 34 & 2 & 17 & 22 & 10 & 3 & 0 & 90 & 0 & 63 & 84 & 0 & 63 \\
\hline 14 & 683 & 65 & 10 & 16 & 19 & 15 & 8 & 0 & 98 & 0 & 77 & 95 & 0 & 73 \\
\hline 15 & 783 & 37 & 107 & 37 & 57 & 41 & 5 & 0 & 142 & 66 & 50 & 132 & 11 & 47 \\
\hline 16 & B11 & 36 & 30 & 23 & 25 & 17 & 8 & 0 & 156 & 0 & 44 & 155 & 0 & 43 \\
\hline 17 & 856 & 25 & 138 & 33 & 88 & 34 & 16 & 0 & 131 & 0 & 67 & 129 & 0 & 67 \\
\hline 18 & 1395 & 52 & 132 & 98 & 144 & 37 & 19 & 0 & 296 & 13 & 77 & 283 & 4 & 75 \\
\hline 19 & $: 419$ & 67 & 161 & 83 & 98 & 99 & 7 & I & 268 & 1 & 64 & 259 & 1 & 63 \\
\hline 20 & 1446 & 60 & 40 & 23 & 61 & 39 & 6 & 0 & 383 & 52 & 66 & 382 & 36 & 66 \\
\hline 21 & 1481 & 68 & 11 & 12 & 21 & 8 & 2 & 0 & 261 & 15 & 48 & 261 & 15 & 47 \\
\hline 22 & 1498 & 86 & 21 & 16 & 32 & 13 & 10 & 1 & 324 & 49 & 449 & 308 & 49 & 388 \\
\hline 23 & 1496 & 31 & 39 & 30 & so & 36 & 5 & 0 & 349 & 19 & 502 & 320 & 19 & 388 \\
\hline 24 & 1496 & 22 & 35 & 40 & 49 & 21 & 4 & 0 & 377 & 121 & 587 & 341 & 109 & 497 \\
\hline 25 & 1499 & 8 & 48 & 57 & 36 & 17 & 4 & 0 & 739 & 125 & 536 & 669 & 70 & 502 \\
\hline 26 & 1498 & 0 & 66 & 56 & 91 & 71 & 21 & $\mathbf{1}$ & 233 & 56 & 1114 & 209 & 38 & 859 \\
\hline TOT & 20428 & 975 & 1120 & 667 & I0Q7 & 543 & 132 & 3 & 4781 & 518 & 4169 & 4488 & 353 & 3587 \\
\hline$\%$ & (95.4) & 4.6) & 5.2 & 3.1 & 4.7 & 2.5 & 0.6 & 0.0 & 22.3 & 2.4 & 19.5 & 21.0 & 1.6 & 16.8 \\
\hline
\end{tabular}

Total number of patterns on file induding those marked deleted $=\mathbf{2 1 , 4 0 3}$

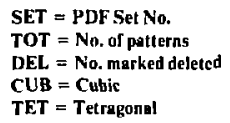

\author{
HEX = Hexagonal \\ ORT $=$ Orthorombic \\ MON = Monocltnic \\ TRI =- Triclinic \\ AST $=$ No, with * and symmetry mark
}

\author{
$C A L=$ No. with $C$ and symmetry mark \\ IND = No. with I and synıntetry mark \\ NS" = " but no symmetry mark \\ NSC $=$ C but no symmetry mark \\ NSI = I but no symmetry mark
}

\section{Q - Base-centered orthorhombic \\ S - Fact-centered orthorhombic \\ M - Primitive monoclinic \\ $N$ - Base-centered monoclinic \\ $Z$ - Triclinic}

The miscellaneous column refers to patterns that have some other symbol in the appropriate column, usually, if not always, a blank. Table 3 was prepared from the inorganic database by program ALLSTAT.

Program ALLSTAT also produced the d-I distribution given in Table 4 and plotted in Fig. 1 , which shows the number of $d-I$ pairs reported on each inorganic pattern in the PDF vs the number of patterns with this number of $\mathrm{d}-\mathrm{I}$ pairs. The prominant spikes in this distribution at lines 39 and 40 are not a true phenomenon. A PDF card image will hold either $40 \mathrm{~d}-\mathrm{I}$ pairs, or 39 with the message " $\mathrm{N}$ lines not included". JCPDS editorial policy over the years has apparently been not to continue a pattern on a second card unless it was of high interest or of high quality. These spikes can also be seen in the distributions given in the next section. Similar spikes near 20,60 , and 80 also reflect the 20-lineper-column layout of a PDF card image. 
Table 2. Organic powder diffraction data base, sets 1-26.

\begin{tabular}{|c|c|c|c|c|c|c|c|c|c|c|c|c|c|c|}
\hline SET & TOT & DEL & CUB & TET & HEX & ORT & MON & TRI & AST & CAL & IND & NE* & NSC & NSI \\
\hline 1 & 140 & 15 & 0 & o & 0 & 0 & 0 & 0 & 0 & 0 & 0 & 0 & 0 & 0 \\
\hline 2 & 76 & 5 & 0 & 0 & 0 & 0 & 0 & 0 & D & 0 & 0 & 0 & 0 & 0 \\
\hline 3 & 109 & 8 & 0 & 0 & o & o & 0 & 0 & o & 0 & 0 & 0 & 0 & 0 \\
\hline 4 & 280 & 23 & 0 & 0 & n & 0 & 0 & 0 & 0 & 0 & 0 & 0 & 0 & 0 \\
\hline 5 & 346 & 32 & 0 & 0 & 0 & 0 & 0 & 0 & 0 & 0 & 0 & 0 & 0 & o \\
\hline 6 & 125 & 7 & 0 & 0 & o & 0 & 0 & 0 & 6 & 0 & 0 & 6 & 0 & o \\
\hline 7 & 239 & 7 & 0 & 0 & 0 & 0 & 0 & 0 & 43 & 0 & 0 & 43 & A & 0 \\
\hline 8 & 305 & 12 & 0 & 0 & 0 & 0 & 0 & 0 & 25 & 0 & 0 & 25 & 0 & 0 \\
\hline 9 & 346 & 4 & 0 & 0 & 0 & o & 0 & 0 & 36 & o & 0 & 35 & 0 & 0 \\
\hline 10 & 324 & 3 & 0 & 0 & 0 & 0 & 0 & 0 & 59 & 0 & 0 & 59 & 0 & 0 \\
\hline 11 & 276 & 0 & 0 & 0 & 0 & o & 0 & 0 & 128 & 0 & 0 & 128 & 0 & 0 \\
\hline 12 & 186 & 1 & 0 & 0 & 0 & 0 & 0 & 0 & 32 & 0 & 1 & 32 & 0 & 3 \\
\hline 13 & 386 & 9 & 0 & 0 & 0 & 0 & 0 & 0 & 27 & 0 & 0 & 27 & 0 & 0 \\
\hline 14 & 256 & 16 & 0 & 0 & 0 & 0 & 0 & 0 & 63 & 0 & 0 & 63 & 0 & 0 \\
\hline 15 & 292 & 7 & o & 0 & 0 & 0 & 0 & 0 & 23 & 0 & 0 & 23 & 0 & 0 \\
\hline 16 & 307 & 2 & 0 & 0 & 1 & 0 & 0 & 0 & 22 & 0 & 0 & 22 & 0 & 0 \\
\hline 17 & 253 & 3 & 0 & 0 & 0 & 0 & 0 & o & 27 & 0 & 1 & 27 & 0 & I \\
\hline 18 & $\mathbf{5 0 7}$ & 4 & 0 & 0 & 0 & 2 & o & 0 & 49 & 0 & 2 & 49 & 0 & 2 \\
\hline 19 & 527 & 6 & 0 & 0 & 0 & 0 & o & 0 & 78 & 0 & 1 & 78 & 0 & 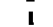 \\
\hline 20 & 561 & 2 & o & 0 & 0 & o & 0 & o & 76 & 0 & 0 & 76 & 0 & 0 \\
\hline 21 & 554 & 10 & 0 & 0 & 0 & 0 & 0 & 0 & 53 & 0 & 0 & 53 & o & 0 \\
\hline 22 & 573 & 20 & 0 & 0 & o & 0 & 0 & 0 & 65 & 14 & 18 & 65 & 14 & 18 \\
\hline 23 & 570 & 8 & 0 & 0 & 0 & 0 & 0 & 0 & 85 & 2 & 57 & 85 & 2 & 57 \\
\hline 24 & 526 & 4 & 0 & 0 & 0 & 0 & 0 & 0 & 64 & 3 & 84 & 64 & 3 & 84 \\
\hline 25 & 521 & 0 & 0 & 0 & 0 & 0 & 0 & 0 & 67 & 3 & 180 & 67 & 3 & 180 \\
\hline 26 & 525 & 0 & 0 & 0 & 0 & 0 & 0 & 0 & 34 & 0 & 92 & 34 & 0 & 92 \\
\hline TOT & 8902 & 208 & 0 & o & 1 & 3 & 0 & 0 & 1062 & 22 & 436 & 1061 & 22 & 436 \\
\hline $\mathscr{m}^{\circ}$ & (97.7 & 2.3) & $\mathbf{0 . 0}$ & 0.0 & 0.0 & 0.0 & 0.0 & 0.0 & 11.7 & 0.2 & 4.8 & 11.6 & 0.2 & 4.8 \\
\hline
\end{tabular}

Total number of patterns on file including those marked deleted $=9,110$

SET $=$ PDF Set No.

TOT $=$ No, of patterns

DEL $=$ No. marked deleted

CUB $=$ Cubic

TET $=$ Tetragonal
HEX = Hexagonal

ORT $=$ Orthorombic

MON = Manoclinic

TRI = Triclinic

AST = No. with " and symmetry mark
CAL = No. with C and symmetry mark

IND = No. with I and symmetry mark

NS* = * but no symmetry mark

NSC $=\mathbf{C}$ but no symmetry mark

NSI = l but no symmetry mark

Table 3. Symmetry vs quality mark distribution for sets $\mathbf{1 - 2 6}$, in ganic powder diffraction data base.

\begin{tabular}{rrrrrrrrrrrrrrrrrrr}
\hline Mark & Misc & C & F & B & T & U & R & H & D & P & Q & S & M & N & $Z$ & Total \\
\hline & & & & & & & & & & & & & & & & & &
\end{tabular}


Table 4. Pair distribution for sets 1-26 of the inorganic powder diffraction data base file.

\begin{tabular}{|c|c|c|c|}
\hline $\begin{array}{l}\text { d-I Puirs } \\
\text { on a puttern }\end{array}$ & $\begin{array}{l}\text { Patterns with } \\
\text { the No. of } \\
\text { d-I pairs }\end{array}$ & $\begin{array}{l}\text { d-I pairs } \\
\text { on a paitern }\end{array}$ & $\begin{array}{c}\text { Patterns with } \\
\text { this No. ci } \\
\text { d-I pail. }\end{array}$ \\
\hline 1 & 0 & 51 & 69 \\
\hline 2 & 0 & 52 & 61 \\
\hline 3 & 5 & 53 & 64 \\
\hline 4 & 29 & 54 & 75 \\
\hline 5 & 16 & 55 & 47 \\
\hline 6 & 135 & 56 & 49 \\
\hline 7 & 181 & 57 & 59 \\
\hline 8 & 243 & 58 & 70 \\
\hline 9 & 277 & 59 & 175 \\
\hline 10 & 376 & 60 & 118 \\
\hline 11 & 392 & 61 & 30 \\
\hline 12 & 469 & 62 & 39 \\
\hline 13 & 523 & 63 & 28 \\
\hline 14 & 610 & 64 & 27 \\
\hline 15 & 547 & 65 & 25 \\
\hline 16 & 625 & 66 & 32 \\
\hline 17 & 565 & 67 & 23 \\
\hline 18 & 602 & 68 & 24 \\
\hline 19 & 648 & 69 & 27 \\
\hline 20 & 790 & 70 & 27 \\
\hline 21 & 689 & 71 & 16 \\
\hline 22 & 632 & $\pi$ & 26 \\
\hline 23 & 605 & 73 & 21 \\
\hline 24 & 536 & 74 & 19 \\
\hline 25 & 536 & 75 & 24 \\
\hline 26 & 563 & 76 & 28 \\
\hline 27 & 517 & 77 & 17 \\
\hline 28 & 520 & 78 & 36 \\
\hline 29 & 509 & 79 & 114 \\
\hline 30 & 522 & 80 & 23 \\
\hline 31 & 431 & B1 & 6 \\
\hline 32 & 471 & 82 & 5 \\
\hline 33 & 400 & $B 3$ & 7 \\
\hline 34 & 400 & 84 & 7 \\
\hline 35 & 355 & 85 & 3 \\
\hline 36 & 357 & 86 & 9 \\
\hline 37 & 309 & 87 & 15 \\
\hline 38 & 374 & 88 & 9 \\
\hline 39 & 1205 & 89 & 17 \\
\hline 40 & 593 & 90 & 2 \\
\hline 41 & 135 & 9] & 2 \\
\hline 42 & 143 & 92 & 0 \\
\hline 43 & 135 & 93 & 3 \\
\hline 44 & 157 & 94 & 0 \\
\hline 45 & 134 & 95 & 0 \\
\hline 46 & 119 & 94 & 2 \\
\hline 47 & 99 & 9 & 0 \\
\hline 48 & 114 & 98 & i \\
\hline 49 & 85 & 99 & 12 \\
\hline 50 & 107 & 100 & 0 \\
\hline
\end{tabular}




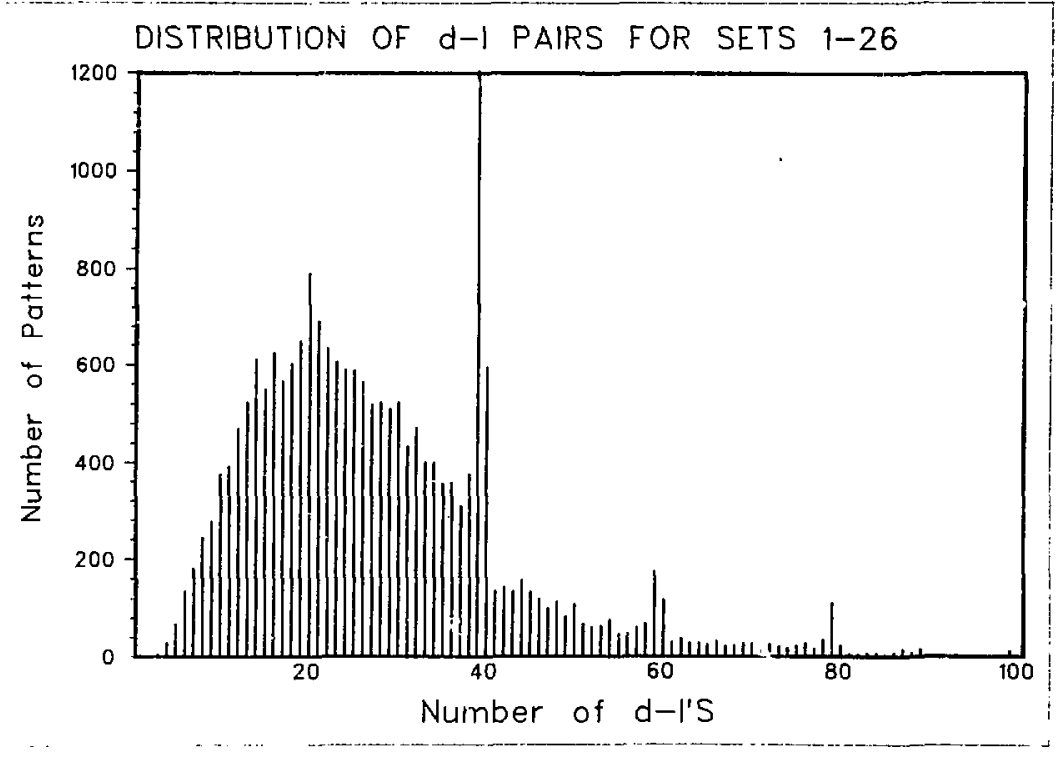

Fig. 1. Distribution of the number of d-l pairs per pattern in sets 1 through 26 of the inorganic P[OF.

\section{ANALISIS OF PATTERNS WITH KNOWN CRYSTAL CLASS}

Several years ago, G. G. Johnson, Jr. of Materials Research Laboratory at Pennsylvania State University was responsible for keypunching a!l the space groups and lattice parameters given on the JCPDS pattern cards. Since then, M. C. Nichols has continued this coding and when we began this study, the known space groups and lattice parameters up through set 24 were available. A program FETCHALL was written to accept these data along with the PDF inorganic master file and to produce eight new files: Cubic (CUB), Tetragonal (TET), Hexagonal and Rhombohedral (HEX), Orthohombic (ORTHO), Monoclinic (MONO), Triclinic (TRI), and two files labeled $X$ and $Y$.

The first si: files contain all the inorganic patterns known to have a particular symmetry, either because of the editorial symmetry mark found on the tape, or because this information had been in- cluded on the PDF card and subsequently coded. The amount of information on each of these patterns varies from known space group and lattice parameters. to nothing more than a crystal-ciass indication. Table 5 summarizes the amount of information known about the patterns on the files. The file labeled " $X$ " contains all those inorganic patterns from sets 1 through 26 with no known quality or symmetry information. The $Y$ file contains all the inorganic patterns with the quality marks "*", "C", or "I", but no further information. Note that because the space group, cell parameter data were only available through set 24 , the $X$ and $Y$ files contain many patterns froin sets 25 and 26. Many of these patterns have known space group and lattice parameters, but the crystal-class data mark was not coded onto the master tape. In fact, patterns from sets 25 and 26 on the six crystal-class files contain unly symmetry marks with no space group or lattice 
Table 5. Symmetry class files.

\begin{tabular}{|c|c|c|c|c|c|c|c|c|c|c|}
\hline FILE & ToT & NOT $F$ & NO CEL & $\mathrm{NC}^{*}$ & NCC & $\mathrm{NCI}$ & CELL* & CELLC & CELLI & $\begin{array}{l}\text { No. with } \\
\text { known parm }\end{array}$ \\
\hline CUD & 3181 & 205 & 121 & 20 & 30 & 61 & 841 & 117 & 290 & 3060 \\
\hline TET & 1973 & 160 & 120 & 43 & 9 & 59 & 491 & 17 & 333 & 1853 \\
\hline HEX & 3125 & 263 & 149 & 17 & 29 & 81 & 784 & 68 & 540 & 2976 \\
\hline ORTHO & 2554 & 271 & 99 & 11 & 6 & 68 & 807 & 56 & 579 & 2455 \\
\hline MONO & 1829 & 286 & 38 & 3 & 2 & 21 & 724 & 57 & 543 & 1741 \\
\hline TRI & 283 & 41 & 2 & 0 & 0 & 1 & 105 & 14 & 95 & 281 \\
\hline$Y$ & 2446 & & & 935 & 113 & 1398 & & & & \\
\hline \multirow[t]{2}{*}{$\mathrm{x}$} & 5037 & & & & & & & & & \\
\hline & & & & & & & & & & 12,416 \\
\hline
\end{tabular}

TOT $=$ No. on fíle

NOT $F=$ No. of pattems not found

NO CEL = No. of patterns witl. symmetry mark but no lattice parameters

$N^{*}=$ No. with * but no parameters

NCC $=$ No, with "C" but no parameters

$\mathrm{NCI}=$ No. with "I" but no parameters

CELL* = No. with ${ }^{*}$ and known parameters

CELLC $=$ No, with $C$ and known parameters

CEI LI = No. with "I" and known parameters

No. with known parms $=$ total No. with known parameters

parameters. These points are reflected in Table 6 which gives a breakdown of the number of patterns in each file by PDF set number.

The patterns referred to in Table 5 as "Not Found" represent patterns marked deleted on the master tape that were skipped in creating the eight files. Thus, a number of patterns tha: had their space groups and lattice parameters keypunched have since been marked deleted. In addition, some of the patterns not found were in the organic file that was not searched.

Table 7 gives the results of symmetry mark vs quality mark analysis for wach of the eight files. These data were obtained by program RSTAT. In addition, RSTAT collected and prepared the data for the d-I pair-distribution analysis of each file, shown in Fig. 2.

To investigate relationships among the $d$ and I values, a program RATIO was written to convert the eight files just described from $d$ values to what we have called $Q$ values. For each pattern, all $d$ values were squared and then divided by the first $\mathrm{d}^{2}$ value to expose geometric relationships within the various symmetry classes. These ratio or $Q$ files are identical to the symmetry class files just described, except that $d$ 's have been replaced by the $\mathrm{d}^{2} / \mathrm{d}^{2}$ ratio. The various analyses of these files to be piresented refer only to the nondeleted patterns from the inorganic PDF sets 1 through 26. The figures were prepared by program RPLOT.

Figure 3 shows the number of patterns with a particular $Q$ for their second ratio (the first ratio in all patterns is, of course, 1.0 , in that all $\mathrm{d}^{2}$ values were divided by the first one). The prominent spikes in these figures are the result of two reflections, with Miller indices in the same order, commonly appearing as the first and second reflections in a pattern. For example, a pattern with $d_{100}$ and $d_{110}$ as the $\int_{11}$ tst two reflections will have its second ratio equal to 0.5. Similarly, Figs. 4 and 5 show the distributions for the 3 rd and 4 th ratios, respectively.

The next sets of figures refer to the intensities of the lines on the $Q$ files. Figure 6 shows the distribution of the value of the intensity of the first three sequential lines on a scale of 1 to 8 for each pattern on the files. The next three sets of figures ( 7 , 8 , and 9) show the distribution of the values of the $\mathrm{d}^{2}$ ratios for the strongest, second strongest, and third strongest lines in each of the patterns on the files. 
Table 6. Number of patterns vs PDF set number for symmetry class files.

\begin{tabular}{|c|c|c|c|c|c|c|c|c|c|c|c|c|c|c|c|}
\hline \multicolumn{16}{|c|}{ Q File } \\
\hline \multicolumn{2}{|c|}{ Cubic } & \multicolumn{2}{|c|}{ Tet } & \multicolumn{2}{|c|}{ Hex } & \multicolumn{2}{|c|}{ Orulto } & \multicolumn{2}{|c|}{ Мопо } & \multicolumn{2}{|c|}{ Tri } & \multicolumn{2}{|c|}{$\mathbf{Y}$} & \multicolumn{2}{|c|}{$\mathbf{x}$} \\
\hline Set & No. & Set & No. & Set & No. & Set & No. & Set & No. & Set & No. & Set & No. & Set & No. \\
\hline 1 & 28 & 1 & 8 & 1 & 18 & 1 & 14 & 1 & 6 & 1 & 1 & $\mathbf{I}$ & 1 & I & 231 \\
\hline 2 & 162 & 2 & 26 & 2 & 50 & 2 & 14 & 2 & 10 & 2 & 0 & 2 & 2 & 2 & 62 \\
\hline 3 & 77 & 3 & 24 & 3 & 41 & 3 & 20 & 3 & 8 & 3 & 0 & 3 & 2 & 3 & 75 \\
\hline 4 & 71 & 4 & 29 & 4 & 56 & 4 & 18 & 4 & 12 & 4 & 3 & 4 & 2 & 4 & 22 \\
\hline 5 & 48 & 5 & 24 & 5 & 35 & 5 & 41 & 5 & 15 & 5 & 3 & 5 & 3 & 5 & 23 \\
\hline 6 & 123 & 6 & 53 & 6 & 109 & 6 & 52 & 6 & 24 & 6 & 7 & 6 & 4 & 6 & 52 \\
\hline 7 & 90 & 7 & 47 & 7 & 74 & 7 & 42 & 7 & 28 & 7 & 8 & 7 & 5 & 7 & 29 \\
\hline 8 & 72 & 8 & 57 & 8 & 64 & 8 & 42 & 8 & 45 & 8 & 8 & 8 & 5 & 8 & 45 \\
\hline 9 & 78 & 9 & 49 & 9 & 86 & 9 & 73 & 9 & 33 & 9 & 11 & 9 & 5 & 9 & 57 \\
\hline 10 & 100 & 10 & 34 & 10 & 59 & 10 & 45 & 10 & 32 & 10 & 6 & 10 & 4 & 10 & 90 \\
\hline 11 & 86 & 11 & 47 & 11 & 56 & 11 & 83 & 11 & 73 & 11 & 8 & 11 & 7 & 11 & 139 \\
\hline 12 & 102 & 12 & 68 & 12 & 123 & 12 & 81 & 12 & 55 & 12 & 22 & 12 & 8 & 12 & 175 \\
\hline 13 & 61 & 13 & 48 & 13 & 85 & 13 & 69 & 13 & 48 & 13 & 6 & 13 & 2 & 13 & 139 \\
\hline 14 & 60 & 14 & 70 & 14 & 95 & 14 & $\$ 4$ & 14 & 69 & 14 & 22 & 14 & 4 & 14 & 212 \\
\hline 15 & 157 & 15 & 103 & 15 & 119 & 15 & 115 & 15 & 58 & 15 & 12 & 15 & 2 & 15 & 183 \\
\hline 16 & 131 & 16 & 117 & 16 & 88 & 16 & 89 & 16 & 68 & 16 & 1n & 16 & 4 & 16 & 276 \\
\hline 17 & 204 & 17 & 84 & 17 & 158 & 17 & 106 & 17 & 78 & 17 & 12 & 17 & 2 & 17 & 185 \\
\hline 18 & 235 & 18 & 182 & 18 & 319 & 18 & 153 & 18 & 113 & 18 & 21 & 18 & 12 & 18 & 316 \\
\hline 19 & 223 & 19 & 144 & 19 & 257 & 19 & 233 & 19 & 119 & 19 & 18 & 19 & 2 & 19 & 364 \\
\hline 20 & 171 & 20 & 128 & 20 & 220 & 20 & 236 & 20 & 154 & 20 & 31 & 20 & 4 & 20 & 450 \\
\hline 21 & 153 & 21 & 90 & 21 & 243 & 21 & 186 & 21 & 149 & 21 & 19 & 21 & 7 & 21 & 574 \\
\hline 22 & 181 & 22 & 121 & 22 & 207 & 22 & 188 & 22 & 231 & 22 & 21 & 22 & 11 & 22 & 460 \\
\hline 23 & 217 & 23 & 149 & 23 & 223 & 23 & 234 & 23 & 187 & 23 & 24 & 23 & 7 & 23 & 43.2 \\
\hline 24 & 261 & 24 & 173 & 24 & 237 & 24 & 262 & 24 & 213 & 24 & 31 & 24 & 13 & 24 & 287 \\
\hline 25 & 49 & 25 & 58 & 25 & 37 & 25 & 18 & 25 & 5 & 25 & 0 & 25 & 1242 & 25 & 89 \\
\hline 26 & 66 & 26 & 56 & 26 & 91 & 26 & 71 & 26 & 21 & 26 & 1 & 26 & 1106 & 26 & 86 \\
\hline TUT & 3181 & TOT & 1973 & TOT & 3125 & TOT & 2554 & TOT & 1824 & TOT & 283 & TOT & 2446 & TOT & 5037 \\
\hline
\end{tabular}




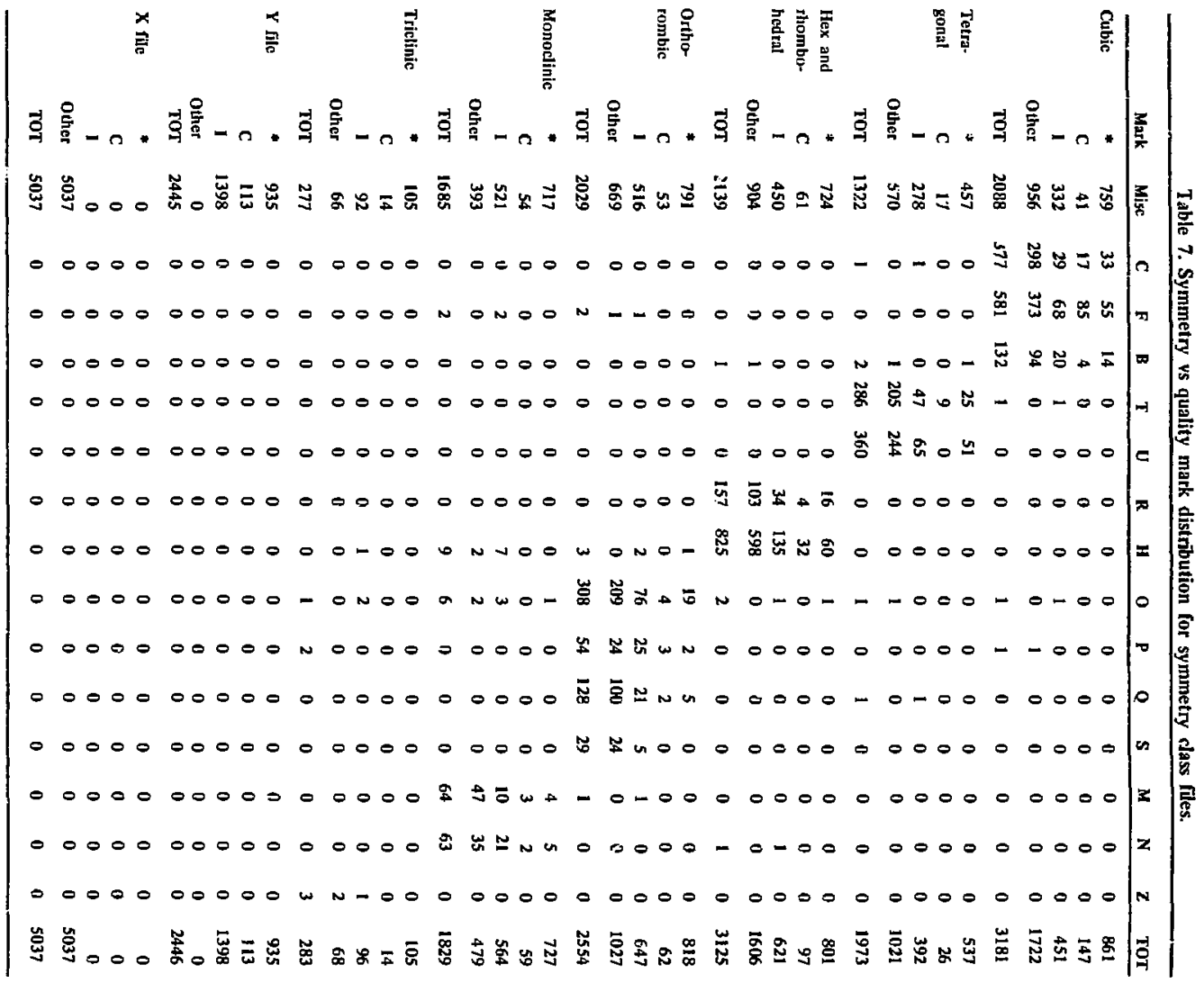




\section{POWDER DIFFRACTION PATTERN QUALITY}

In the last phase of this str.dy we evaluated the quality of a number of ihe fatterns in the Powder Diffraction File. To do this, we postulated several functions and obtained the de Wolff $M_{y_{0}}$ function : from the litera:ure. Many of these functions required a knowledge of systematic extinctions for each pattern, thus restricting us to those patterns with both latlice parameters and space groups $n n$ the files described in the previous section. We needed the space group symbols to generate systematic extinctions and the lattice parameters to calculate theoretical 20 positions, and thus were faced with an extensive amount of editing. All of the original errors as well as those that resulted from the various stages of keypunching became painfully obvious. To reduce the size of this task we restricted our studies to only the highest (cubic) and lowest (triclinic) symmetry cases.

Programs SPCUB and SPTRI were written to merge the space group and cell parameter data with sets 1 through 24 of the inorganic PDF master tope. These programs selected the cubic and triclinic patterns. respectively, and also checked the space groun symbols against all valid symbols. In addiion, they checked, corrected, and added the space group number saarched for any inconsistenries, and meiged the d-I information into the binary files, PDFCL'B and PDFTRJ. When all editing and error correcticn was complete, the files contained 2080 cubic and 292 triclinic patterns with dit needed information. Table 8 lists the frequency of occurrence of the various space groups encountered in the PDF cubic and triclinic files. This tabulation is similar to others for all crystal systems ${ }^{6,7}$.

To cunpare the average data found in the PDF to known high-quality data, we encoded the PDF numbers for all the cubic patterns determined by the National Bureau of Standards $\$$. The patterns that correspond to these numbers were extracted from the cubic file PDFCUB to form a file ralled PDFNBSCUB which intains 315 patterns. The IIBS patterns as they appear on the PDF master taps were affected by editorial procedures. All digits in $\mathrm{d}$ more than three places after the decimal had been eliminated, causing $\Delta 20$ errors of more than $0.5 \mathrm{deg}$ at high angles. Another difficulty arises from different values of the $x$-ray wavelengths used over the years. Both of these problems can be avoided if the measured 20 values instead of a functionally derived quantity like $d$ are used in publications and computer databases.

Because we still needed a set of accurate. reliable powder patterns for comparison purfoses,
Table 8. Distribution of cubic and triclinic space groups.

\begin{tabular}{|c|c|c|}
\hline $\begin{array}{l}\text { No. of palterns } \\
\text { with this space } \\
\text { group }\end{array}$ & $\begin{array}{c}\text { Space } \\
\text { group xymbol }\end{array}$ & $\begin{array}{c}\text { Space } \\
\text { group number }\end{array}$ \\
\hline \multicolumn{3}{|l|}{ Cubic } \\
\hline 1 & $\mathbf{P 2 3}$ & 195 \\
\hline 3 & $\mathbf{F 2 3}$ & 196 \\
\hline 1 & 123 & 197 \\
\hline 76 & P2(1)3 & 198 \\
\hline II & $12(1) 3$ & 199 \\
\hline 4 & PM43 & 200 \\
\hline 4 & PN3 & 201 \\
\hline 47 & FMS & 202 \\
\hline 3 & FD3 & 203 \\
\hline 15 & IM3 & 204 \\
\hline 95 & PA3 & 205 \\
\hline 42 & IA3 & 206 \\
\hline 8 & P4(2)32 & 208 \\
\hline I & $F 4(1) 32$ & 210 \\
\hline 2 & 1432 & 211 \\
\hline 3 & P4(3)\}2 & 212 \\
\hline 10 & $\mathrm{P} 4(1) 32$ & 213 \\
\hline 3 & If(1)32 & 214 \\
\hline 10 & P4JM & $2 t 5$ \\
\hline 73 & $F-43 M$ & 216 \\
\hline 31 & $\mathrm{I}-43 \mathrm{M}$ & 217 \\
\hline 14 & P-43N & 218 \\
\hline 5 & $F-43 C$ & 219 \\
\hline 49 & I-43D & 220 \\
\hline 289 & PMSM & 221 \\
\hline 3 & PN3N & 222 \\
\hline 68 & PHON & 223 \\
\hline 10 & PN3M & 224 \\
\hline 645 & FM3M & 225 \\
\hline 27 & FM3C & 226 \\
\hline$\mp 03$ & FD3M & 227 \\
\hline 4 & FD3C & 228 \\
\hline $\begin{array}{l}39 \\
81\end{array}$ & $\begin{array}{l}\text { IM3M } \\
\text { IA3D }\end{array}$ & $\begin{array}{l}229 \\
230\end{array}$ \\
\hline
\end{tabular}

Triclinic

$\begin{array}{rlr}149 & \mathbf{P}_{1} & \mathbf{i} \\ 115 & \mathbf{P}_{1} & \mathbf{2} \\ \mathbf{1} & \mathbf{C}_{\mathbf{1}} & \\ 1 & \mathbf{A}_{1} \\ 1 & \mathbf{F}_{1} & \\ \mathbf{2} & \mathbf{i}_{1} & \\ 23 & \mathbf{C}_{\mathbf{i}} & \end{array}$

we keypunched the complete set of 336 cubic NBS patterns and 38 high-quality triclinic patterns. The NBS patterns in their original published form are accurate to the level of the measurements made and 
should be as ascurate as any available powder diffraction data. These two files, NBSCLBB and NBSTRI, complete the data sets analyzed in this section. The notations on Figs. 10 through St mean the followitig:

- PDF (UR/C. These are the 2080 cubic patterns obtained from the PDF mister tape and contained in file PDICUB.

- PDP-NAS CURIC. These are the 254 cubic NBS patterns as extracled from the PI)F master lape and contained in file PDFNBSCUB.

- TRUR: NBS CUBIC. These are the 336 cubic NBS patterns as punched from the original publications and contained in file NBSCUB.

- PDF TR/ClIN/C. These are the 315 triclinic patterns as extracted from the PIDF master lape and contained in file PDFTRI.

- NBS TR/CLINIC. These are the 38 highquality triclinic patterns obtained from NBS publications and de Wolff palterns from the PDF: card file.

We wrote five programs to analyze these five data files. The programs generited all of the possibic reflections for each paltern read, and then eliminated all systematic extinctions required by the space group symbol. It also rejected any pattern with lines that could not be matched to a calculated line within $0.50-\mathrm{deg} 20$. This relatively mild rejection criterion eliminited over 400 of the PIDF CUBIC patterns. Table 9 gives the actual number of patterns that could be indexed and that were used to produce all the figures in this section.

With the exception of Fig. 10, the figures in this section fall into five types labeled (a) through (e). Figures 11 to 15 show plots characterizing four of the five data files and testing some ideas of the authors. For the functions tested in these plots, the PIPF-NBS cubic file is identical to the true NBS cubic data file. Thus, there are only four illustrations in each of these figures. Figures 16 through 51 test the properties of the nine different functions along with their average values. The functions iested are:

$$
\begin{aligned}
\text { I. } \Delta d & =\left|d_{\text {exp }}-d_{\text {calc }}\right| . \\
2 . \Delta 2 \theta & =\mid 2 \theta_{\text {exp }}-2 \theta \text { calc } \mid . \\
\text { 3. } \Delta 2 \theta_{\mathrm{rms}} & =\sqrt{\left|2 f_{\mathrm{exp}}-2 f_{\mathrm{culc}}\right|^{2}} .
\end{aligned}
$$

4. $N / N$ poss. This is the ratio of the numaber of a particular diffraction line (called $N$ or $N_{o b s}$ ), starting from the lowest angle reflection, to the number of possible lines, excluding systematically absent reflections. We refer to this quantity as "RATIO".

$$
\text { 5. } F_{N}=\frac{1}{\sqrt{\Delta 201}} \frac{N}{N_{\text {poss }}}
$$

The $N$ in $F_{N}$ refers to the number of the last diffraction line used in the ealculation and is called $A V .2$ THETA MERIT. F $F_{N}$, which resulted from this wark, is described in Rel. 9.

6. $F_{N}(R M S)$ is similar to $F_{N}$, but uses the root mean square average $\mathbf{} 2 \theta$ in its definition, referred to as RMS 20 MERIT.

\begin{tabular}{|c|c|c|c|c|c|c|c|c|c|c|}
\hline \multirow[b]{2}{*}{ Filc } & \multirow{2}{*}{$\begin{array}{l}\text { No. } \\
\text { in fils }\end{array}$} & \multirow{2}{*}{$\begin{array}{c}\text { No. with } \\
\text { space } \\
\text { group } \\
\text { and cell }\end{array}$} & \multirow{2}{*}{$\begin{array}{c}\text { Cal- } \\
\text { culated } \\
\text { patterns }\end{array}$} & \multirow{2}{*}{$\begin{array}{l}\text { No. } \\
\text { to be } \\
\text { indexed }\end{array}$} & \multicolumn{6}{|c|}{ Evaluated } \\
\hline & & & & & $\overline{|\Delta 20|}$ & $\mathbf{N}_{\text {poss }}$ & $\mathbf{F}_{\mathbf{N}}$ & $\mathbf{M}_{\mathbf{N}}$ & $\mathbf{M}_{20}$ & $\mathbf{R}$ \\
\hline PDF-cubic & 3087 & 2080 & 117 & 1638 & 0.091 & 0.766 & 16.39 & 1109 & 40.1 & 0.156 \\
\hline PDF-NBS cuhic & 258 & 254 & $\mathbf{0}$ & 252 & 0.032 & 0.833 & 29.29 & 1447 & 77.5 & 0.057 \\
\hline NBS cubic & 339 & 336 & 5 & 326 & 0.015 & 0.822 & 74.76 & 2396 & 124.9 & 0.025 \\
\hline PDF TRJ & 315 & 292 & 17 & 229 & 0.053 & 0.268 & 9.77 & 285 & 9.0 & 0.206 \\
\hline NBS TRI & 38 & 38 & $\mathbf{0}$ & 37 & 0.019 & 0.490 & 33.00 & 624 & 14.8 & 0.072 \\
\hline
\end{tabular}

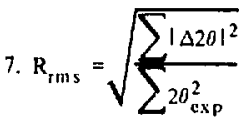

Table 9. Characteristics of the cubic and triclinic files and average values of functions evaluated for all lines of patterns to be indexed. 


$$
\text { 8. } M_{20}=\frac{Q_{20}}{2|\Delta Q| N_{p a: s}}
$$

where $Q_{20}=\frac{1}{d^{2}}$ of the 20 th line.

This is a function derived by de Wolff and proposed for use in cvaluating the reliability of a computerindexed cell (see Ref. 5 ).

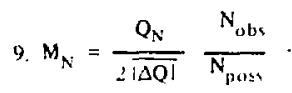

This tunction was our attempt to generalize the de Wolff $\mathrm{M}_{20}$ function so that it could be evaluated at any line number $(N)$.

Tat le 9 lists average values for several of the above iuncrions evaluated cver all of the lines in each pattern. Using all lines in a pattern to evaluate any of the merit functions presents a problem for low-symmetry materials becuuse the number of possible diffraction lines increases dramatically with diffraction angle. Thus, the matching of calculated and observed lines gets artificially better for high diffraction angles. This "easy matching" phenomenon causes an artificial lowering of $\Delta 2 \theta$ (or 3Q) for high line numbers. Figure 10 shows the average $F_{N}$ figure of merit as a function of $N$ for PDF triclinic data. The incteasing value of $F_{N}$ above line 30 results from the "easy matching" phenomenon. To avoid this artificial increase in the merit functions evaluated, we decided to limit the calculations to the first 30 lines of those patterns with more than 30 lines. Thus, in all of the figures that refer to an average function for a pattern, this function was evaluated up to the 30th or last line if the pattern contained less than 30 lines.

Figures 11 and 12 show the distribution of cubic lattice parameters and the $\bar{a}$ parameters for triclinic at 0.2 and $0.1 A$ resolution. The elustering of parameters for cubic materials is the rcsult of a large number of common structure types in the file. Figure 13 shows the distribution of the intensities of all the diffraction lines on the four files. These distributions are of interest for varjous theoretical considerations of pattern searching procedures. Figure 14 shows the average | $\Delta 2 \theta$ | of each line on the files as a funtion of the intensity of the line. These plets indicale, somewhat surprisingly, that the error :: measuring the position of a diffraction line for average quality data is independent of the line's inlensity. $A$ corretation does appear to exist for the high-quality cubic data. However, because these patterns are uriformly reported to high angle where the rounding of $d$ values has its most serious effect in $|32 A|$ and where reflections tend to be of linear intensity, this may be an artificial correlation. Bearuse the intensity of the data were not coded onto the true NBS cubic file, this effect cannot be verified, although the lack of a correlation in Figure 14(d) for high-quality triclinic data appears to indicate that the cubic correlation is filse. Figure 15 shows the $F_{N}$ meril function vs $P D F$ set number. Because these sets are released once per year, they indicate that average pattern quality has not significantly inproved with time. The higher values of $F_{N}$ in some of the earliest sets are not totally accuratc because JCPDS editors have systematically repliaced all but the best patterns over the years.

Figures 16 through 24 show average values for the nine functions evaluated up through line numbers $10,20,30,40$, and at the last line, whatever its number may be. These functions were evaluated for cubic primitive $(P)$, face-centered $(F)$, and bodycentered (J) Bravais lattices as well as for triclinic primitive (P), any face-centered $(F)$, and all faces or body-centered (?; , In addition, these functions were evaluated for all the data on each file and for those patterns marked with an asterisk. Because we encoded the data for the true NBS file, no asterisks were attached; ior the PDF-NBS file all patterns are marked with an asterisk. The existence of nonprimitive triclinic patterns may appear unusual, but several s-idinic cells have been reported in this manner. The slashed bars on top of the average bars represent the standard deviations of the averages.

Figures 25 through 33 show distributions of the average values for the nine functions evaluated at the 30 th or last line, whichever comes first. To obtain these distributions, the average values were rounded off to the nearest ordinate value. For these figures, the values of the functions were divided into 100 intervals.

Figures 34 to 42 show average values for the nine functions evaluated at the line numbers from 5 to 55. The prominant increase in the merit functions and decrease in the error functions at line number 40 apparently results from the editorial policy previously described, to only include complete data for patterns of better-than-average quality. Another possibility is that authors publishing complete patterns may systematically have taken more care in 
measuring the pattern. The singie life in the $M_{30}$ plots reflects the fact that this function is only defined at the 20th line.

Figures 43 to 51 show average values of the nine functions cvaluated at differcnt $d$ values, starting with the largest. The gererally increasing error functions and decreasing merit functions as d gets smaller is the result of the same editorial procedure that forced the independent encoding of the original high-quality cubic and triclinic patterns. The rounding off of $d$ values on the magnetic tape database has its most severe effect at high angles and low $d$ values. Note that pattens throughout this study were only evaluated up to the limit of the $\mathrm{Cu}$ Kex sphere of reflection. Thus, these plots do not extend lower than $d=0.78$. 

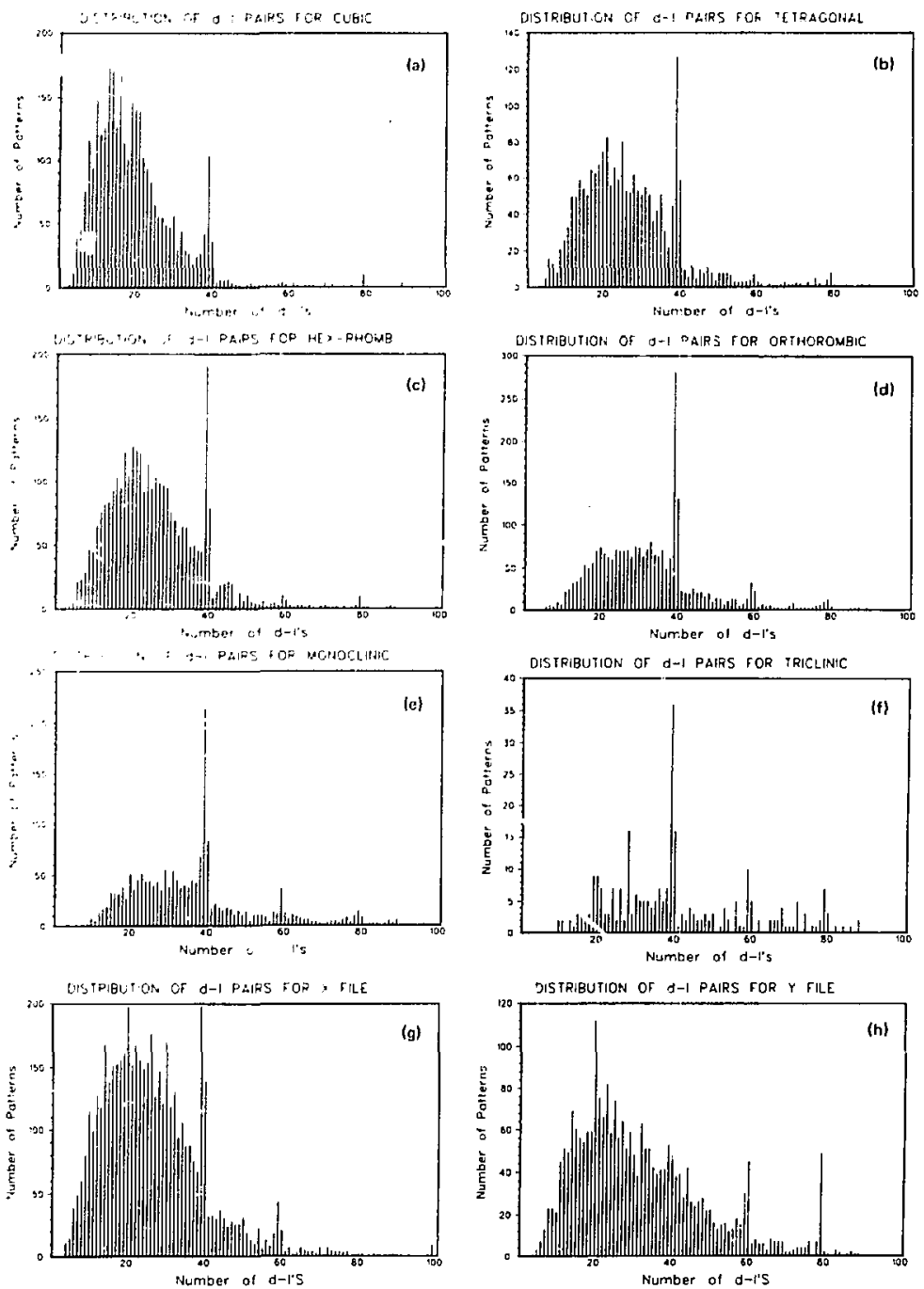

Fig. 2. Distribution of the number of d-I pairs per pattern on the tight crystal-ciuss Jiles. 

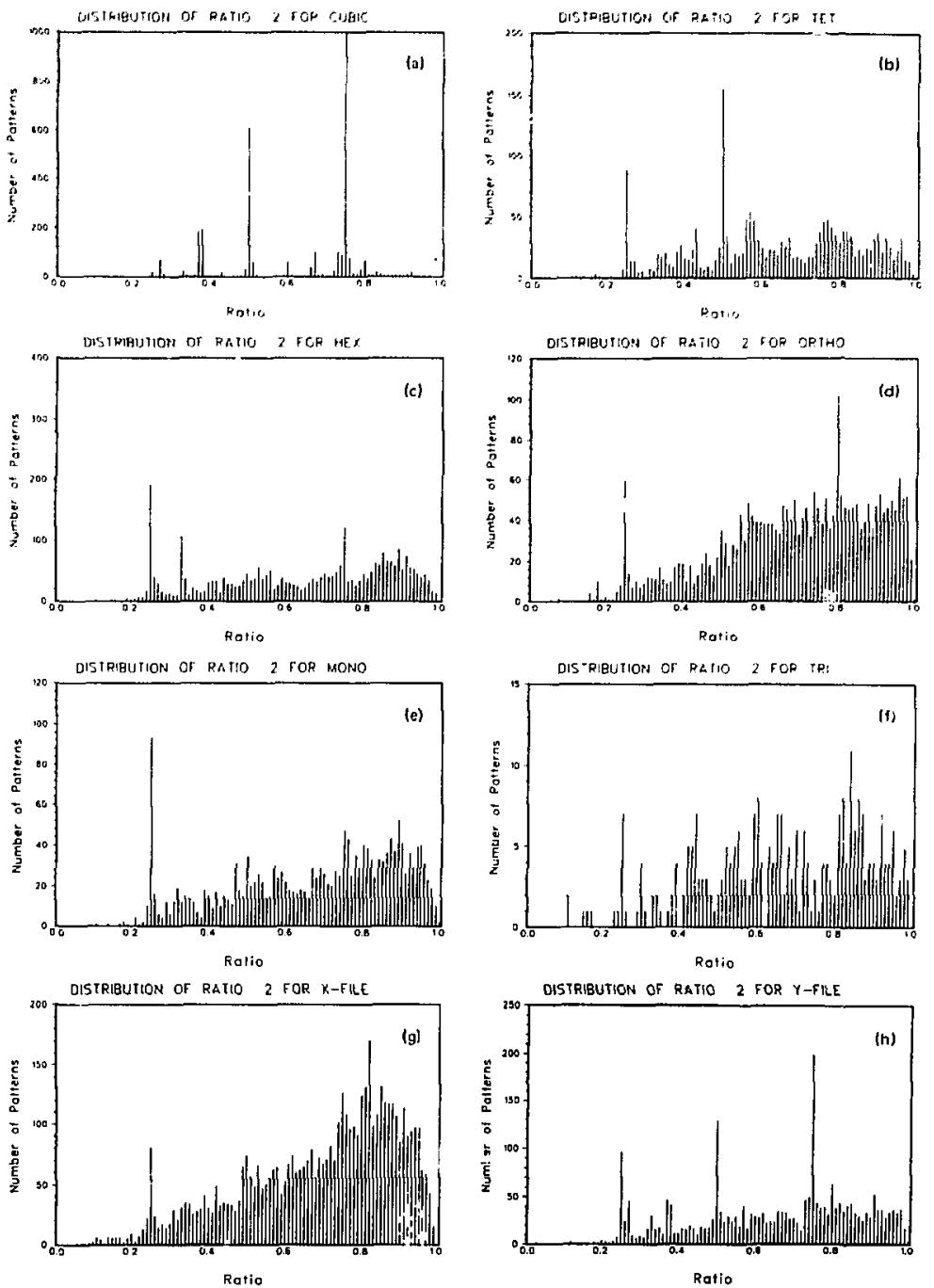

Fig. 3. Disurlbution of the value of $d_{2}^{2} / d_{1}^{2}$ for the eight crysta!-cless files. 

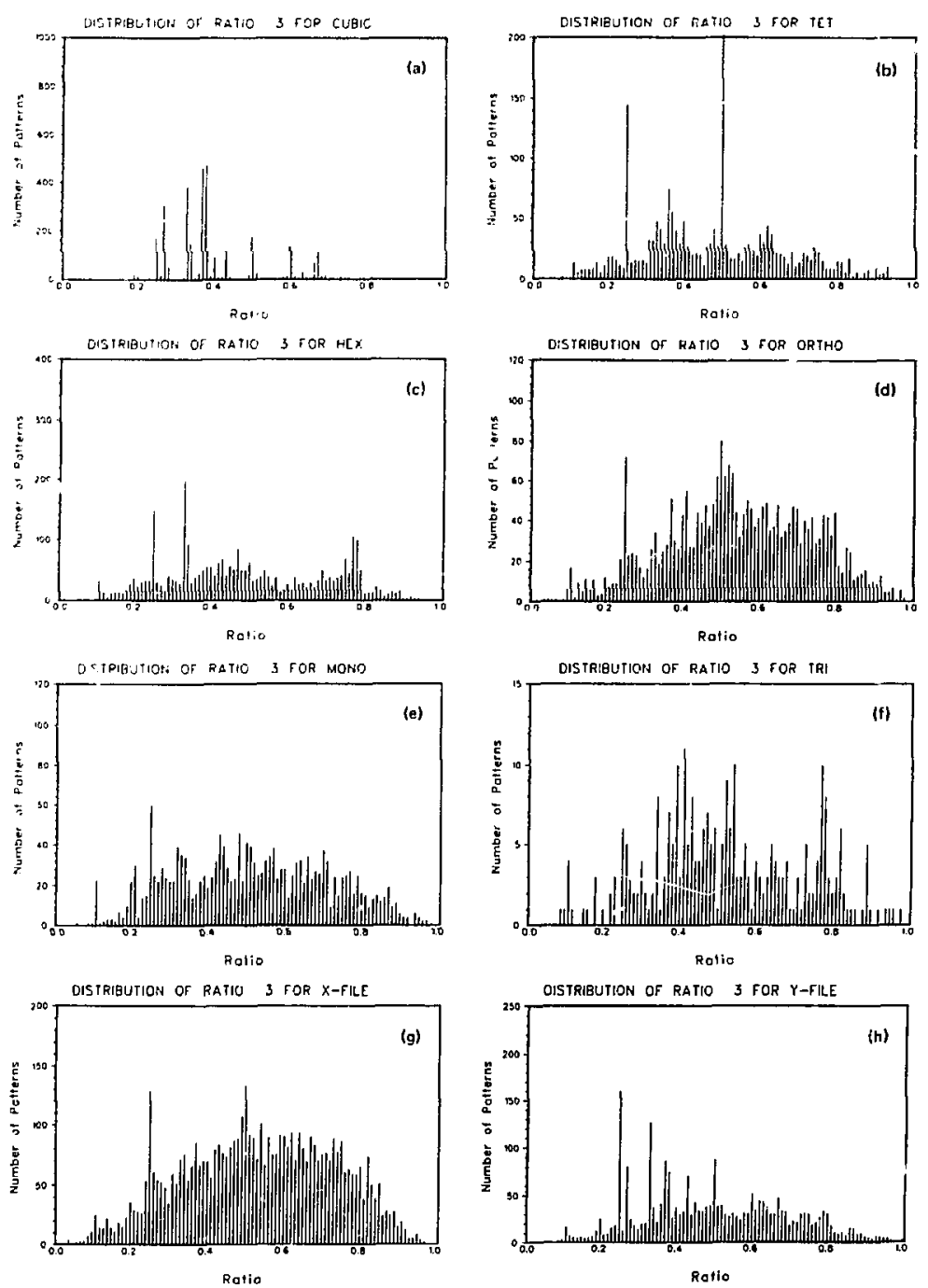

Fig. A. Distribution of the value of $\mathrm{d}_{3}^{2} / \mathrm{d}_{1}^{2}$ for the eight crystat-cinss files. 

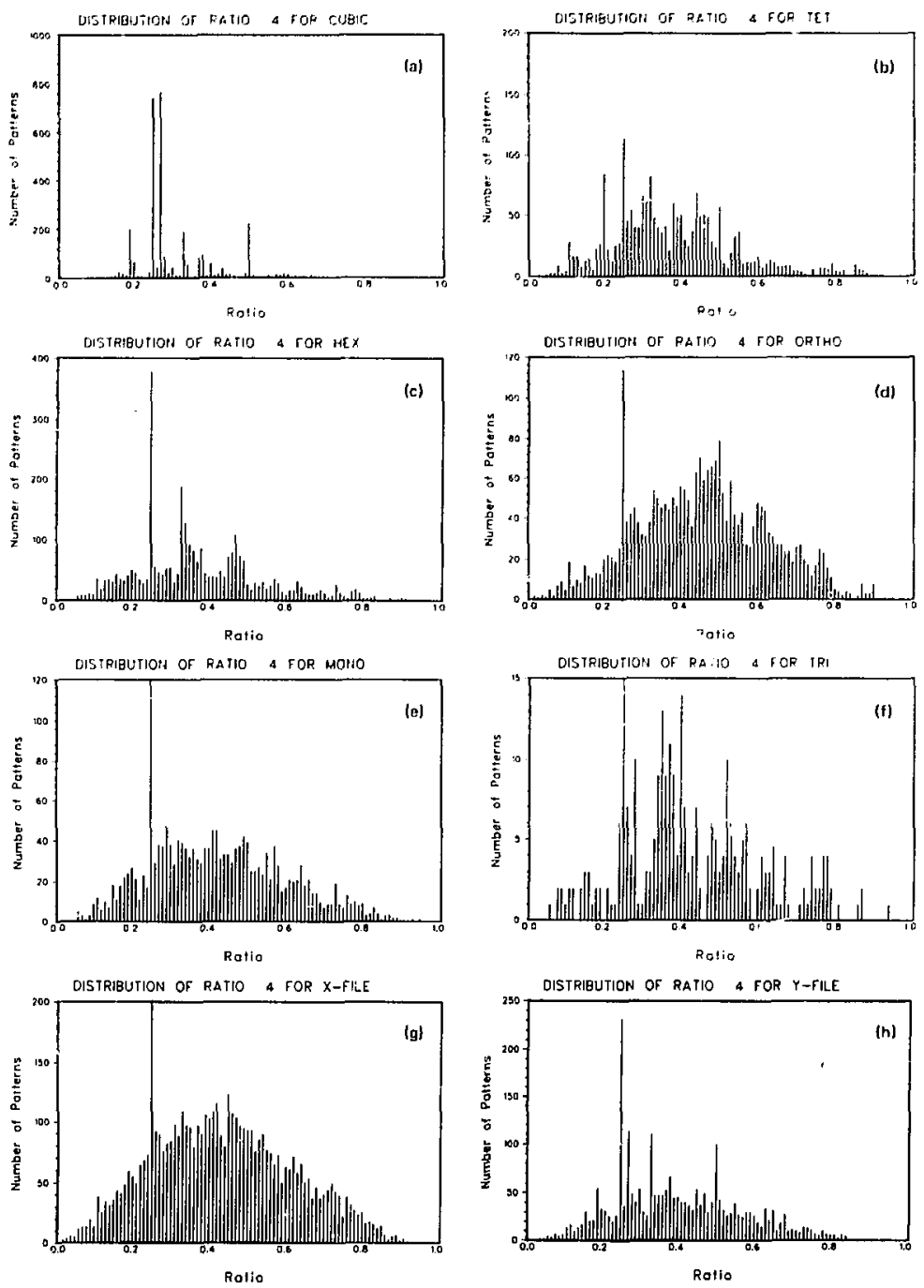

Fig. 5. Distrlbution of the values of $\mathrm{d}_{4}^{2} / \mathrm{d}_{1}^{2}$ for the eight crystsal-class files. 

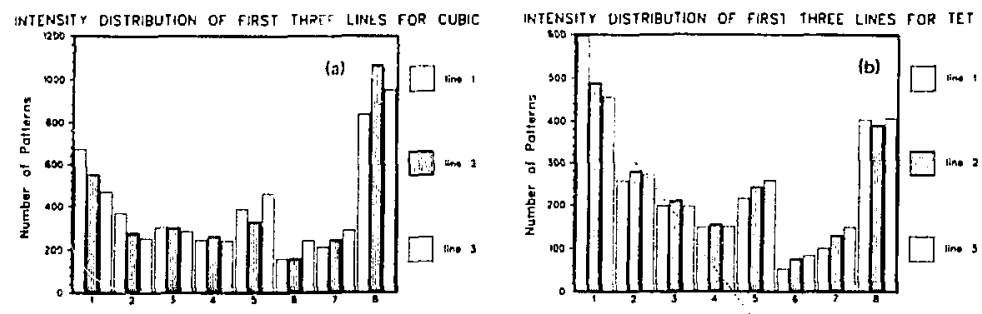

iniensity on a scole of $B$

Iniensily on a segle st 8

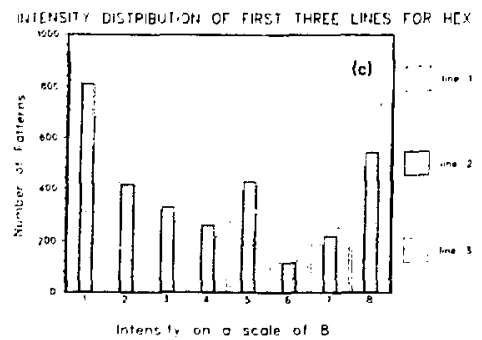

MTEASITY DISTPIBUTION OF FIRST THPEE LINES FOR MONO

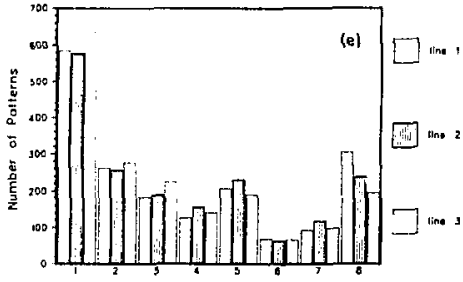

Intensity on a scale of 8

INTENSITY DISTRIBUTION OF F':SI THREE LINES FOR ORTHO

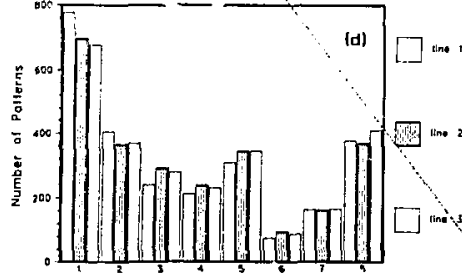

Intensity on a scole of 8

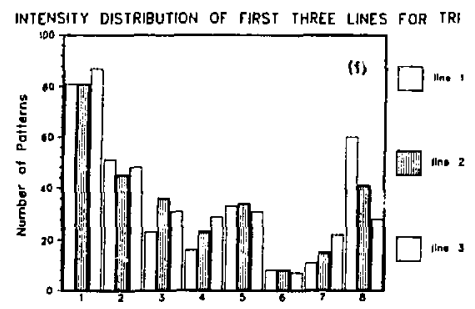

intensily on a scale of $\mathbf{6}$

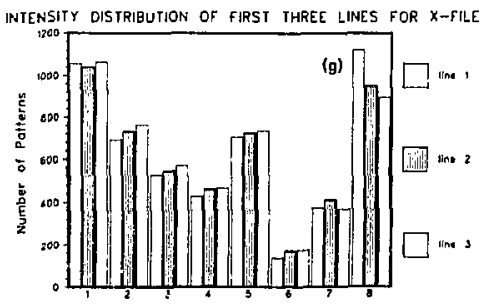

intensily on a scole of 8

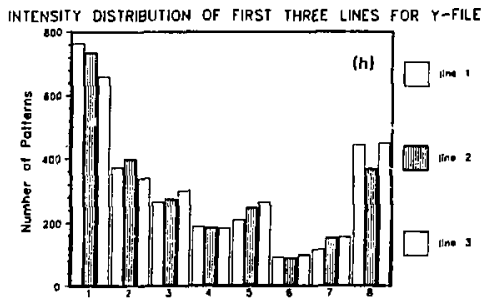

Intensity on a scale of 8

Fig. 6. Distribution of the intensities of the first three lines in each pattern for the eight ciystal-class files. The intensity of tine 1 is represented by the bar farthest to the left in exch group of three. 

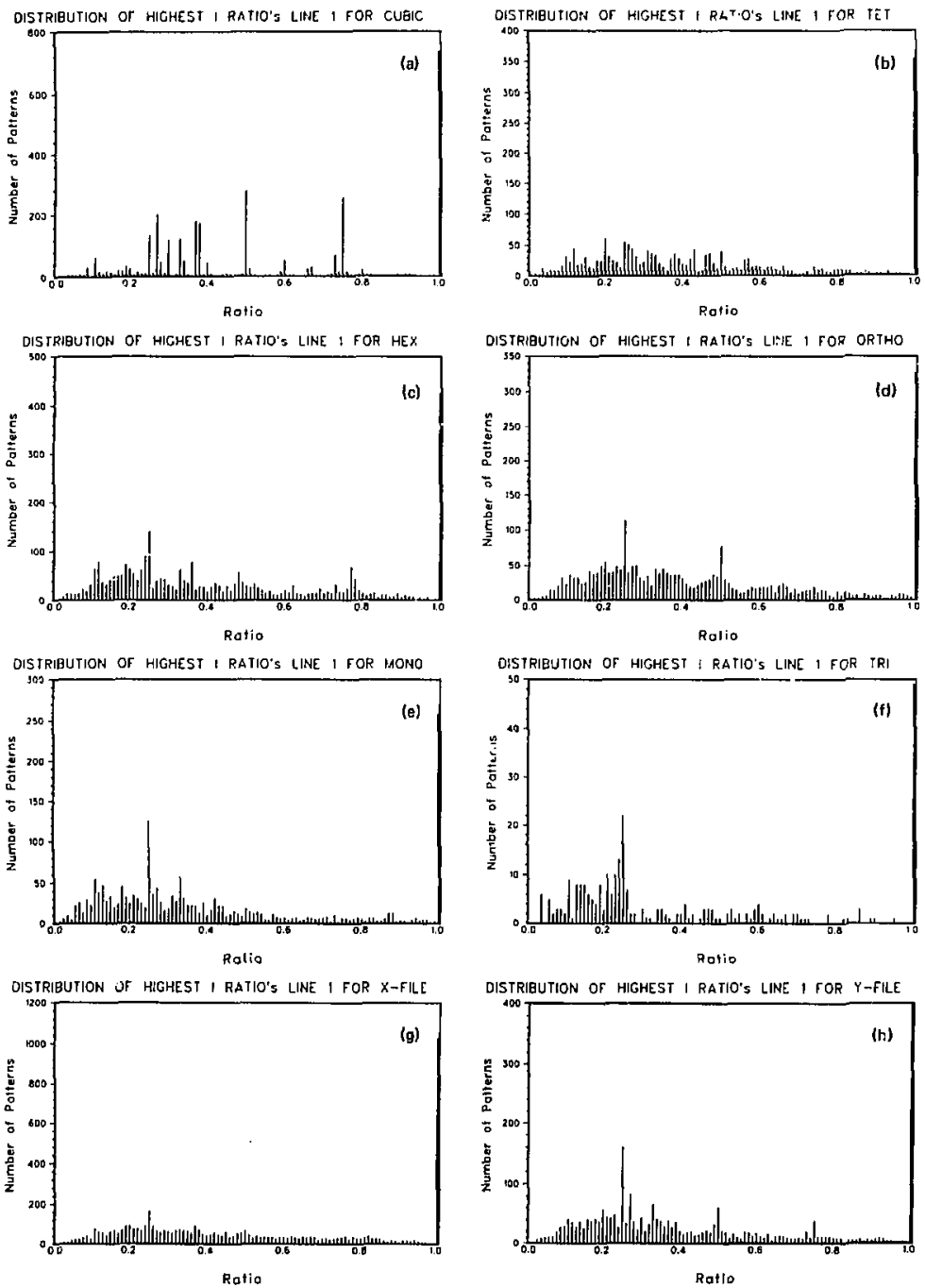

Fig. 7. Dbaribution of the $\mathrm{d}^{2} / \mathrm{d}_{1}^{2}$ values for the most hatense line in the patterns on the eight crystal-class files. 

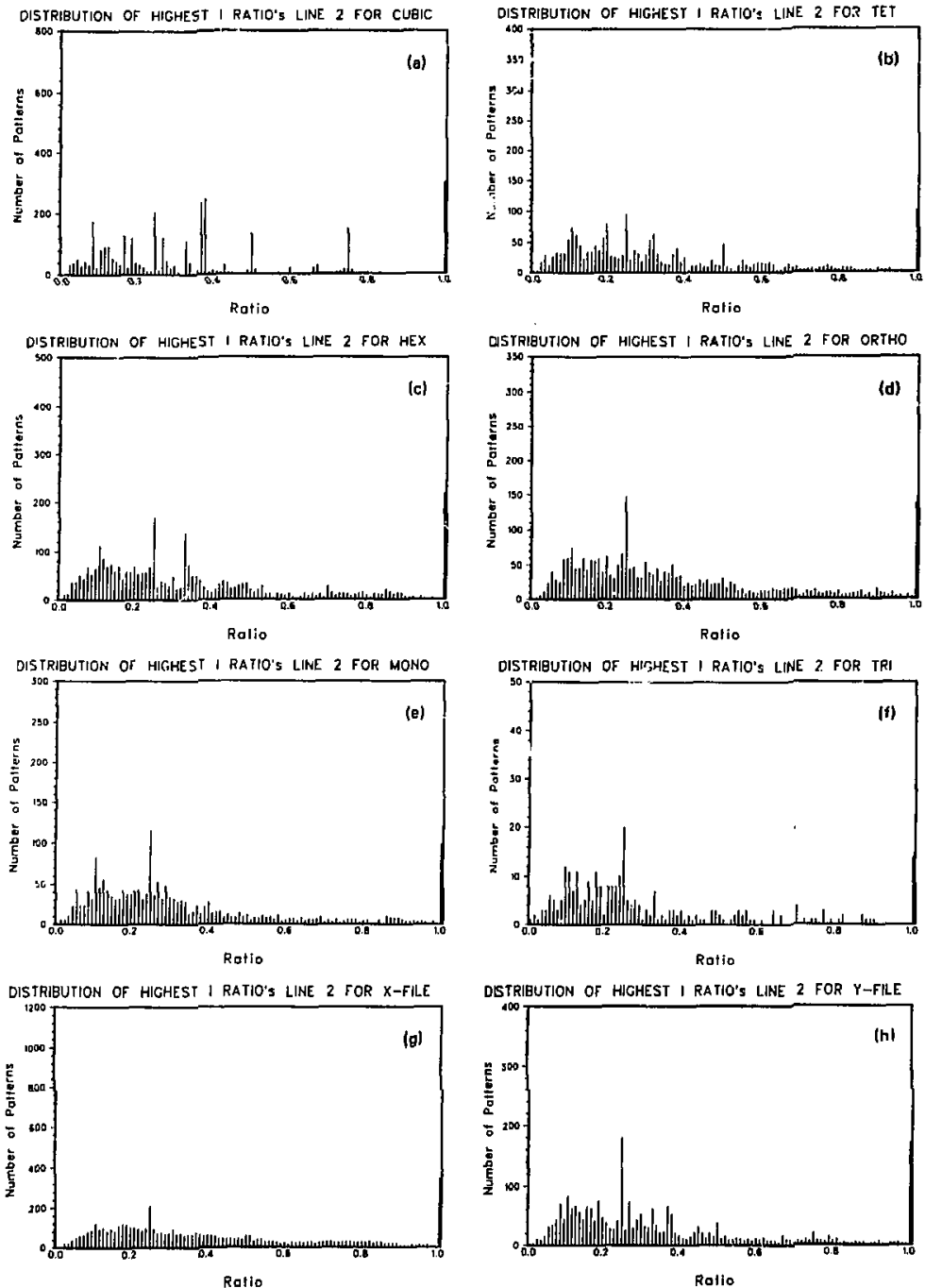

Fig. 8. Dlatribution of the $d^{2} / d_{1}^{2}$ values for the wecond most intense tine in the patterns on the eight cryastatiass fles, 

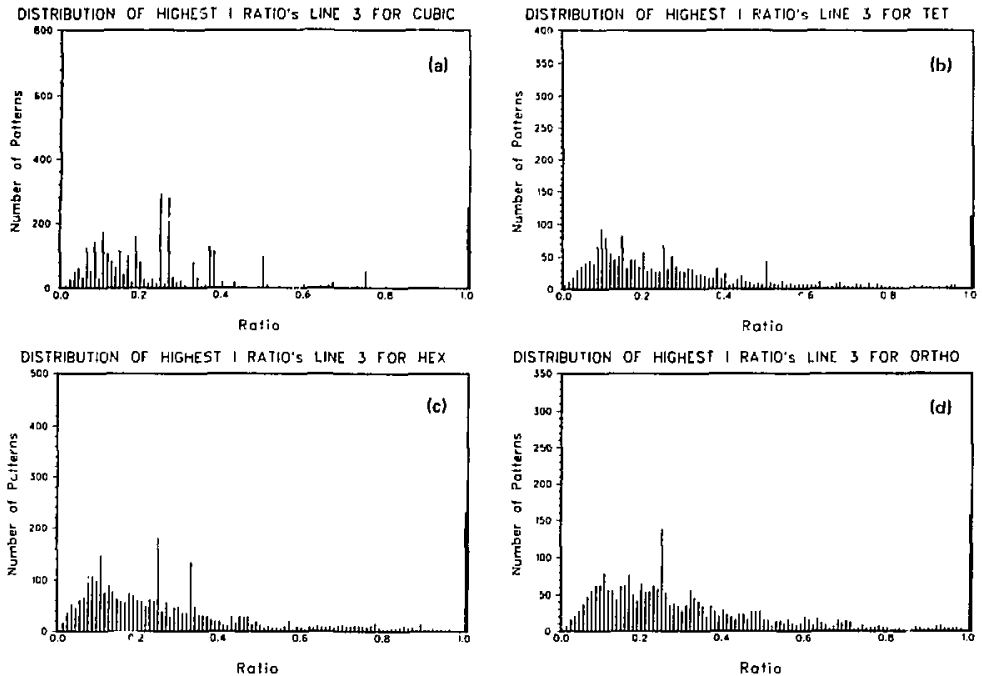

DISTRIEUTION OF HIGHEST I RATIO'S LINE I FOR ORTHO
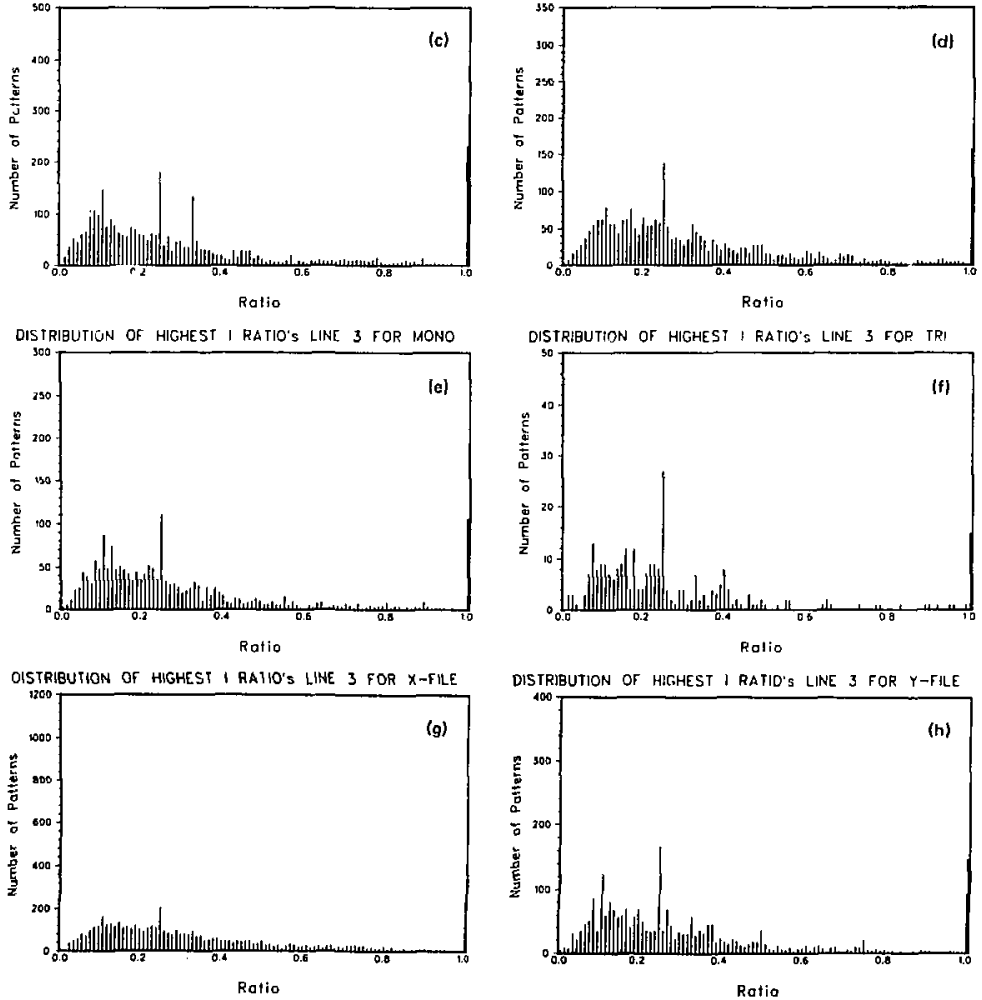

Fig. 9. D/stribution of the $\mathrm{d}^{2} / \mathrm{d}_{1}^{2}$ values tor the thind most intense line in the pattems on the eight crystal-slass files. 


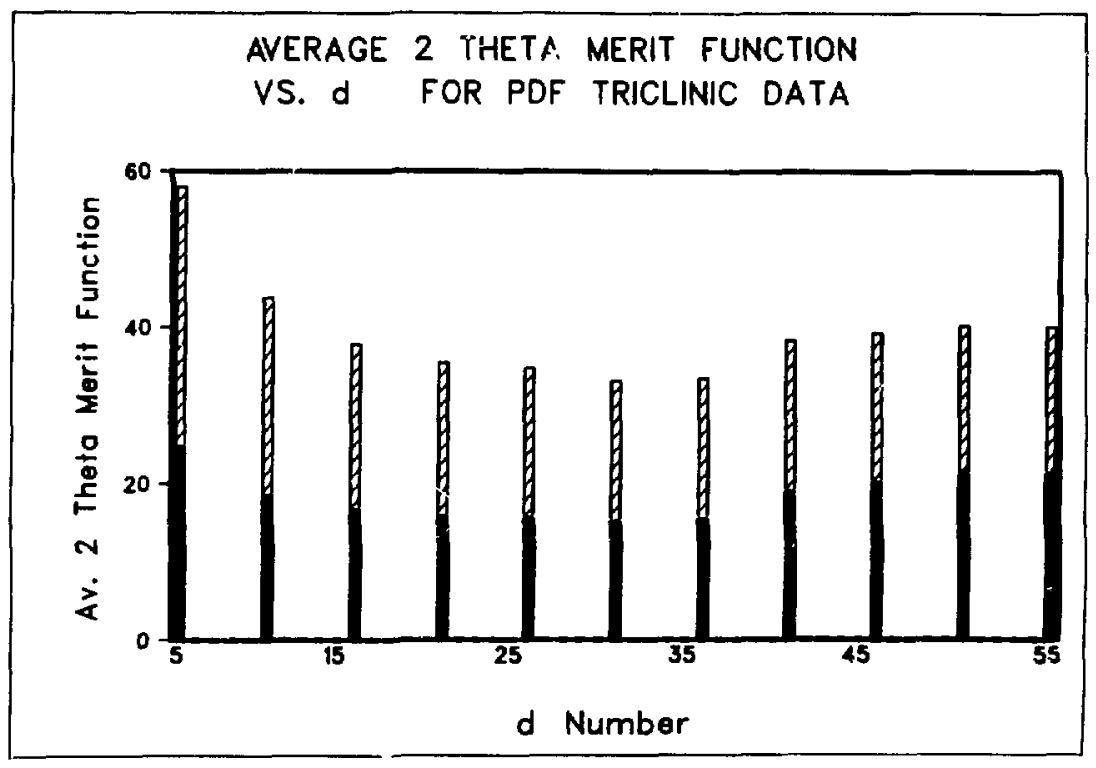

Fig. 10. Distribution of average values of the merit function $F_{\mathrm{N}}$ vs line number in each pattern. Slashed bars represent the standard deviation of average $f$, values. 
QUALITY OF POWDER DIFFRACIION STANDARDS

POF Cubic Dato: CELL CONSTANT DIST.

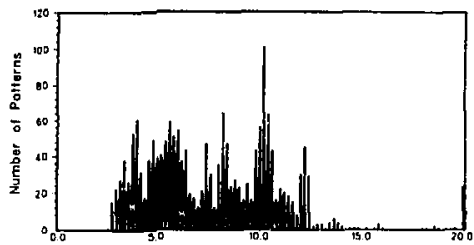

CELL CONSTiTI

OUALITY OF POWDER DIFFRACTION STANDAROS PDS Triclinic Doto: CELL CONSTANT DIST.

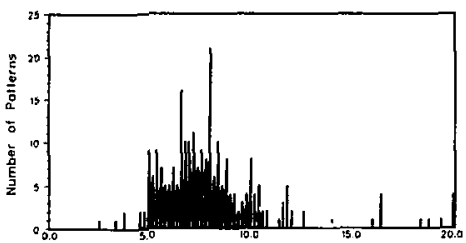

CELL CONSTANT

(c)

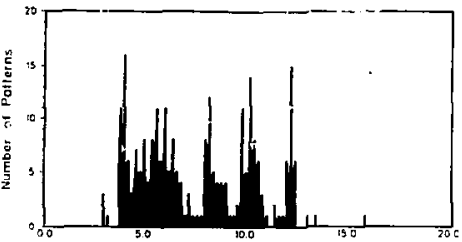

cent consiant QUALITY OF POWDER DIFFRACTION STANDARDS NQS Trictinic Datis : cell constont dist.

(d)

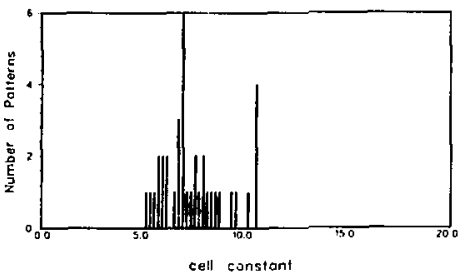

Fig. 11. Distribution of cubic Iattice parameters and aiclinic a values at $0.2 A$ resolution.

OUALITY OF POWOER DIFFRACTION STANDARDS FDF Cubic Data : CELL CONSTANT DIST.

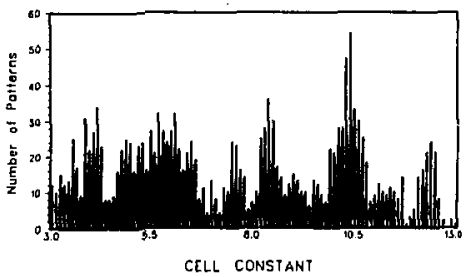

OUALITY OF POWDER DIFFRACTION STANDARDS PDF-NBS Cubic Dato : cell constant dist.

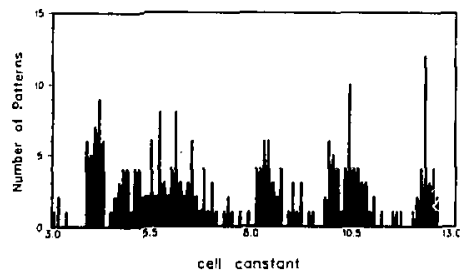

QUALITY OF POWT:R DIFFRACTION STANDARDS (b) POF Triclinic Data : CELL CONSTANĩ DIST.

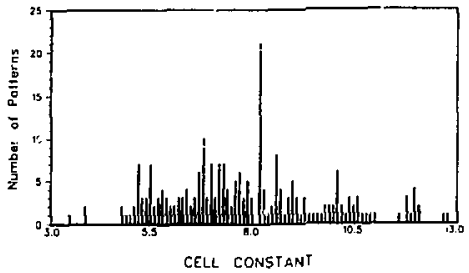

OUALITY OF POWDER DITFRACIION STANDARUS NES Triclinic Uato: cell constant dist.

(d)

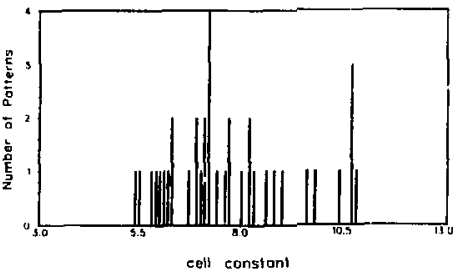

Fiz. 12. Dtstribution of cubie Inttlce parametes and triclinic values at $0.1 A$ resolutlon. 
QUAL'TY OF POWDER DIFFRACTION STANDARDS

PDF Cubic Dolo : INTENSITY OISTRIOJIION

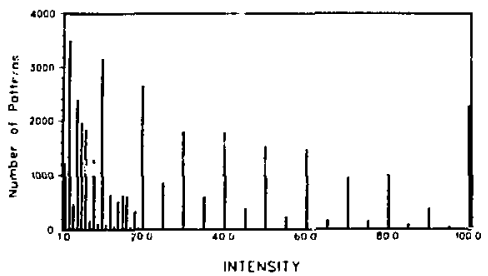

OUALITY OF POWDER DIFFRACIION STANDARDS

PDF Triclinic Do10: intensity distributinn

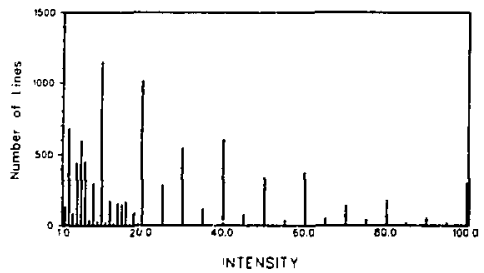

(c)
QUALITY OF POWDER DITERACTION STANDARDS

POF-NES Cubic Dato: intensit dislribution

(2)

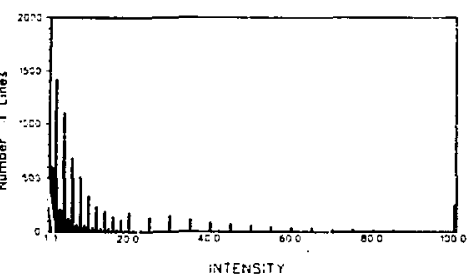

GUALITY OF POWDER DIFFRACTION SJANDARDS

NBS Triclinic Doto : intensity distrihution

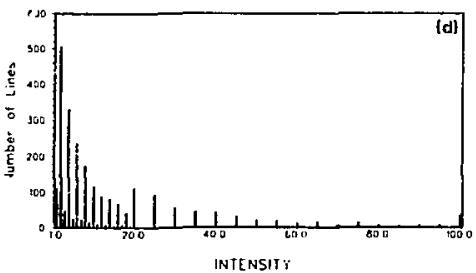

Fig. 13. Distribution of the intensities of the diffraction liaes on the two cabic and two triclinic files.

AV. DELTA 2 IHETA VS. INTENSITY ALL PDF CUBIC DATA

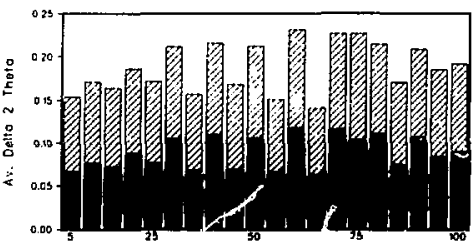

Intensity in intervols of 5

AY. OELTA 2 THETA VS. INTENSITY PDF TRICLINIC DATA

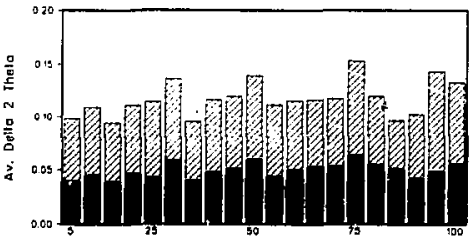

Intensity in intervals of 5

(a)
AV OELTA 2 THETA YS MTERSITY AL: PEF-NGS CUEC DATA

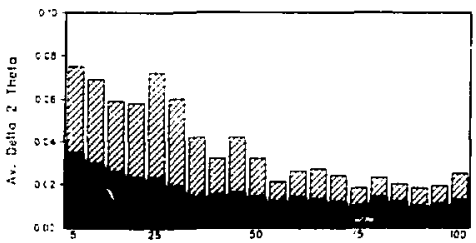

latensity in in ervols of 5

AV. I LLTA 2 THETA VS. INJENSITY NSS IRICLINIC DAT.

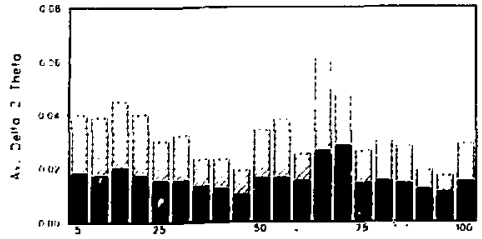

Intensily in intervals of 5

Fig. 14. Avernge $2 \theta$ error as a function o, line intensity. Sashed bars represent siandard deviations. 


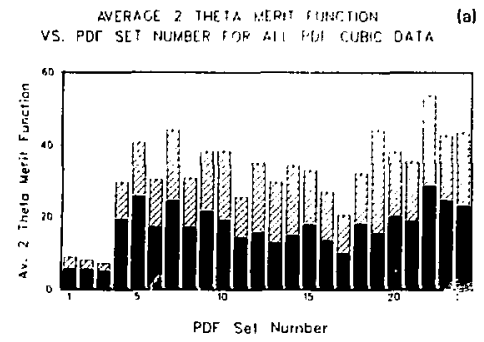

AVERAGE 2 THETA MERIT TUNCTION

VS. POF SET WUMEER FOR ALL PUT IRICLIAIC DATA

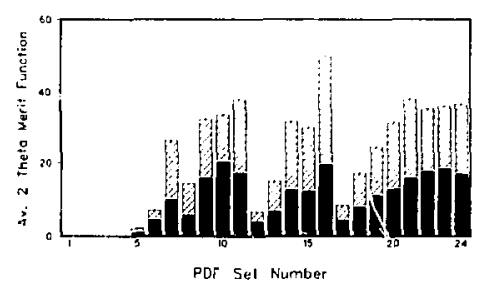

(a)

(c)

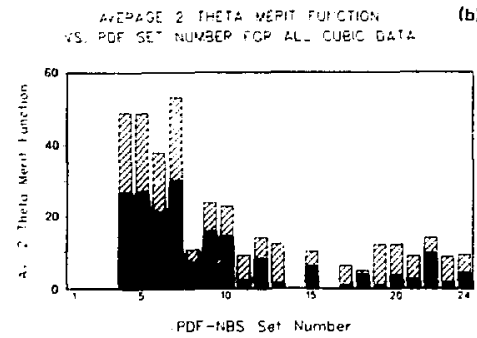
WERAGE 2 THETA MERIT FUNIETION (d) YS. POF SEI HULEER FOR IABS IRICLINHC WATA

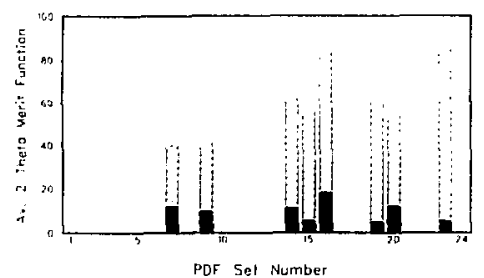

Fig. 15. Average values for the figure of merit $F_{\mathrm{N}}$ as a function of the PDF set number. Slashed bars represent standard deviations. 
QUALTTY OF POWDER OIFFRACTION STANDAROS POF Cubic Data : Delta d* 10000

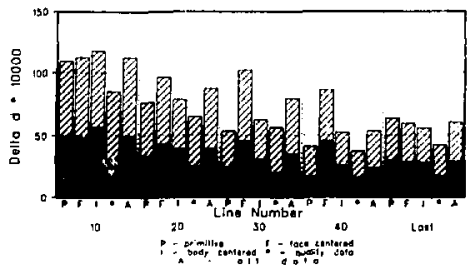

QUALIFY OF POWDER DIFFRACIION STANDARDS True NES Cubic Doto :Delta d 10000

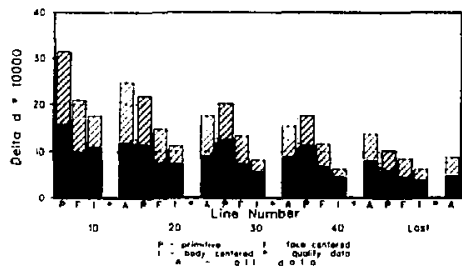

GUALITY OF POWLER DIFFRACTION STANDAROS

(c)

FEF-A:BS fubic Dato: Delto d 10000

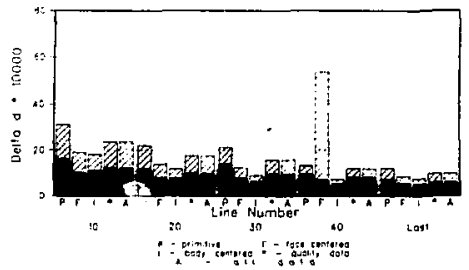

GHALITY CF POWDEF DIFFRACTION STANDARDS

fDF Triclínic ngta : Dello d 10000

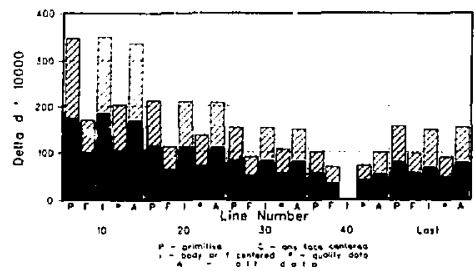

TUALITY QF POWOER DIFFRACTION STANDARDS NBS Triclinic Dato : Delto d 10000

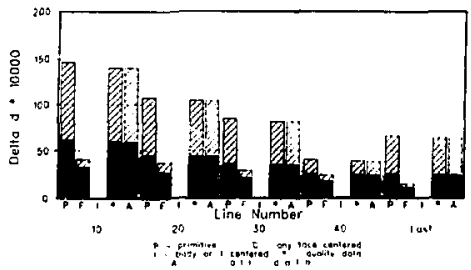

Fig. 16. Averngae value of I id / as a function of line number, iattice type, and PDF quality mark. Slashed bars represent standard deviations. 
OUALITY OF POWDER DIFFRACTION STANOAROS Por Cubic Dato : Dalta 2 Theta

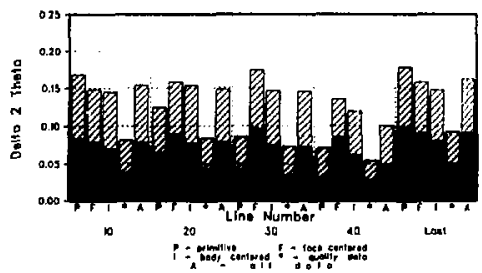

OUALITY OF POWOER DIFFRACTION STANDARDS True NaS Gubic Doto :Della 2 Theia

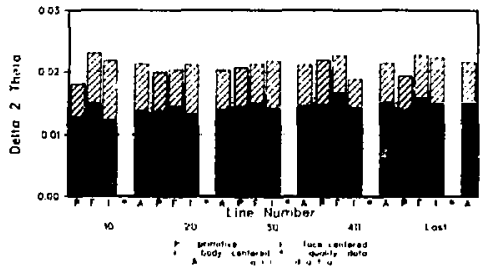

OUALITY OF POWOER DIFFRACTION STANOAROS

(c) PCF-HaS Cubic Data: Delto 2 iheto

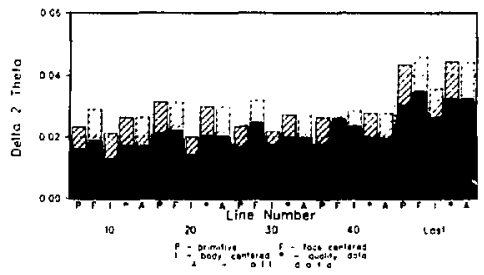

QUALITY OF POWDER DIFFRACTION STANDAROS (d) PDF Triclinic Doto : Delta 2 Theto

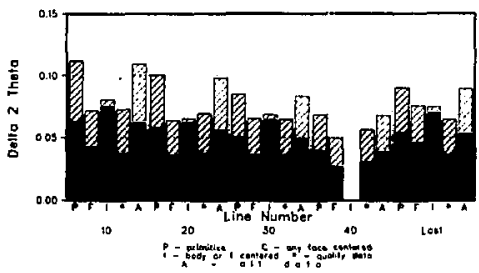

OUALITY OF POWDEF OIFFRACTION STANOAROS NBS Triclinic Data Della 2 The'u 
QUALITY OF POWDER 'JIFTRACTION STAMOAROS

PDr Cubic Dota. RMS Delso 2 Theta

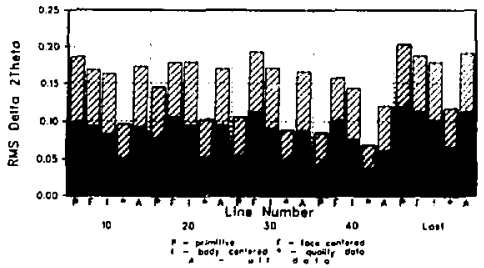

OUALITY OF POWDER DIFFRACTION STANOAROS

True NBS Cubic Dato :HM! linlto ? Ineto

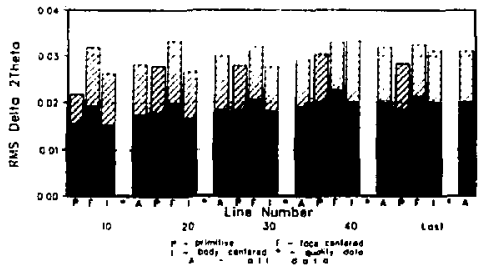

(b)

CUALITY OF POHDED riffrpactory standarDS

(c)

FOF-1.ES Cubir Dale : Fus Det:a itheto

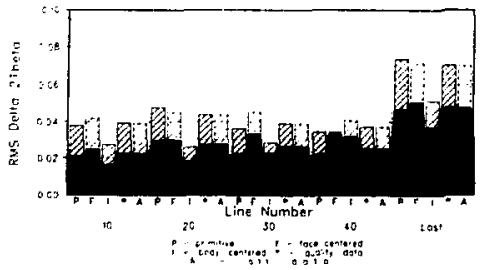

OUALITY OF POWDER DIFFRACTION STANDARDS PDF Trielinic Dala: RMS Della 2 The to

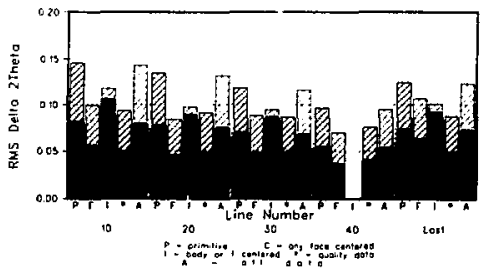


QUALTT OF POWDER DIFFRACTION STANDARDS PDF Cubic Data : Nobs / NFoss 0

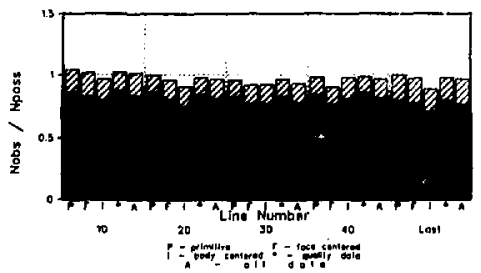

QUALITY OF POWDER DIFTRACTION STANDAROS True NBS Cubie Dala :Nobs / Nposs

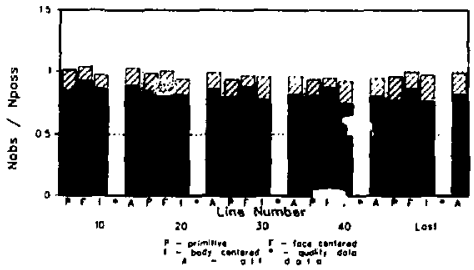

\section{3}

QUALITY OF POWDER DIFFRACTION SIANDAROS

PDF-NaS Cubic Data : Nots, iposs

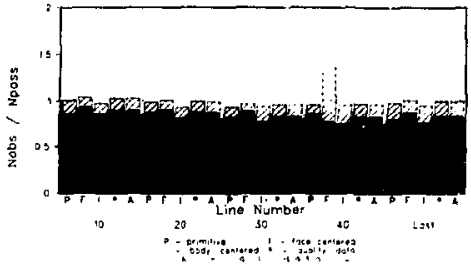

QUALITY OF POWDER DIFFRACTION STANDARDS PDF Triclinic Dola : Nobs / Nposs"100

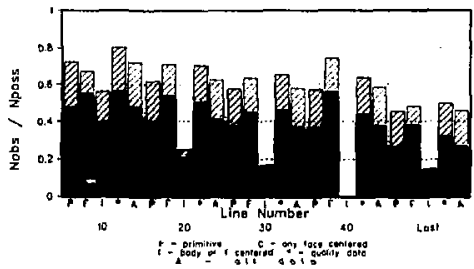

(c)

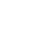

\section{c)}


QUALITY OF POWDER DIFFRACTION STANDARDS PDF Cubic Dalo : AY. 2 THETA MERIT

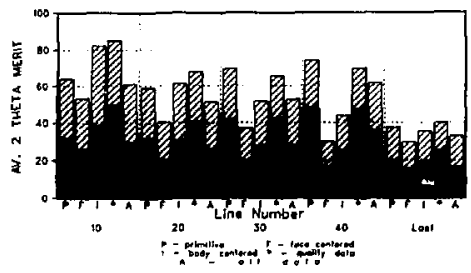

CUALITY OF POWDER DIFFRACIION STANOAROS True NBS Cubic Doto :AV. 2 IHETA MERIT

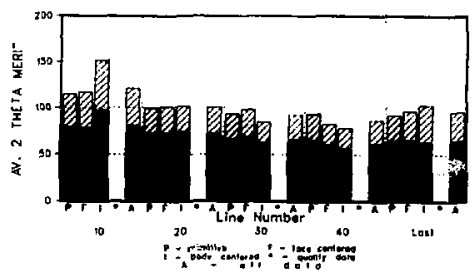

OUALITY OF POWDER DIFFRACTION STANDAROS

PDF-NBS Cubic Dato : AV, 2 THETA MERIT

\{c\}

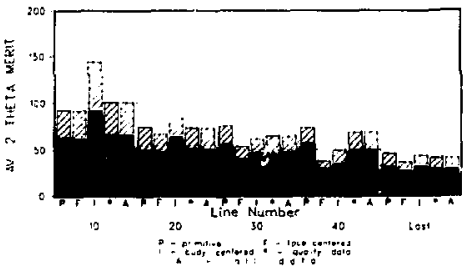

OUALITY OF HOWDER DIFFRACTION STANDARDS PDF Triclinic Dato: $A V .2$ THEJA MERIT

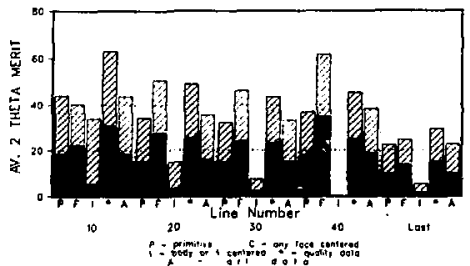

OUALITY OF POWDER DIFFRACTION STANDARDS NBS Triclinic Dola : AV. 2 JHETA MERIT

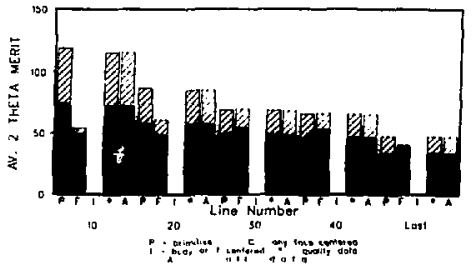

Fig. 20. A verage value of $F_{N}$ as a function of line mumber, lattice type, and PDF quality mark. Stasind bars represent standhid deviations. 
OUALITY OF POWDER OIFFRACTION STANDARCS PDF Cubic DOTO: RISS 2 IHETA MERIT

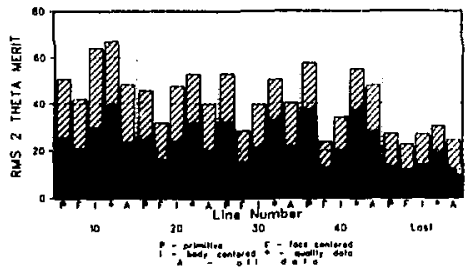

OUALITY OF POWUH DIIFAR IITH TIAHOARDS

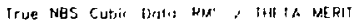

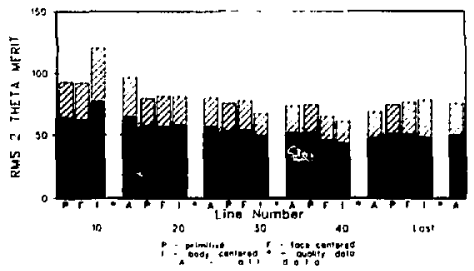

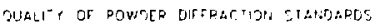

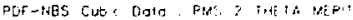

(c)

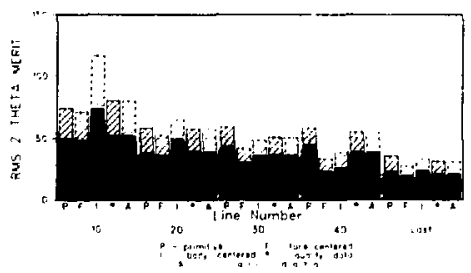

OUALHTY OF POWDER DIFFRACTION STANDARDS PDF Iriclinic DOto : RMS 2 THETA MERIT

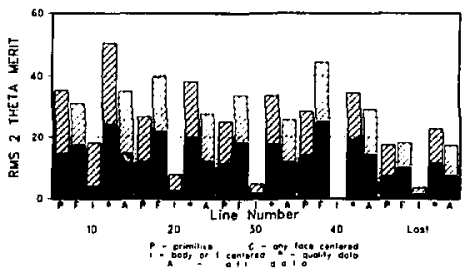

OUALITY OF POWDER OIFFRACIION STANIMRTES NBS Iriclinic Doto: RMS 2 IHIIA MIRIt

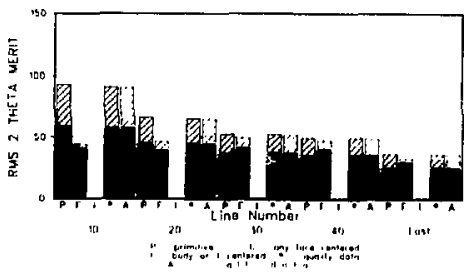

Big. 21. A verage value of root mean square $F_{N}$ as a function of line number, lattice type, and PDF quality mark. Slastred bars represent staniard deviations. 
OUALITY OF POWOER DIFFRACTION STANDAROS PDF Cubic Doto : R-rms

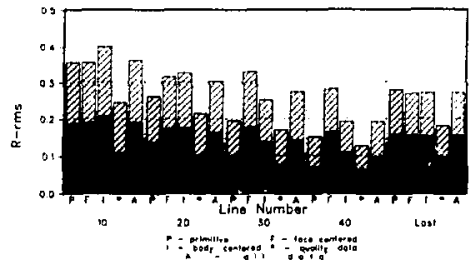

OUALITY OF POWOER DIFRACITON STANDAROS irue NBS loubir $(1,2)+m$

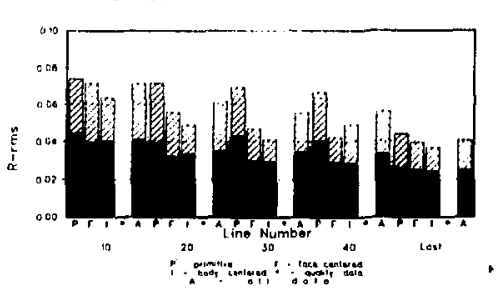

(b)

DURLIT OF FCWDE DIFFACTIOM STANDARDS

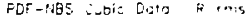

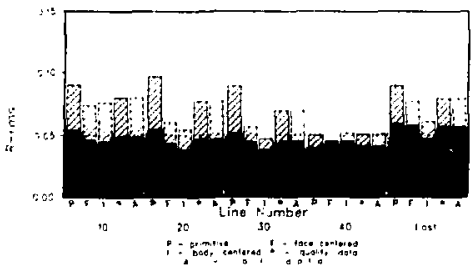

QUALITY OF POWDER DIF-RACTION SIANDARCS puF Trielinic Dolc : R-rms

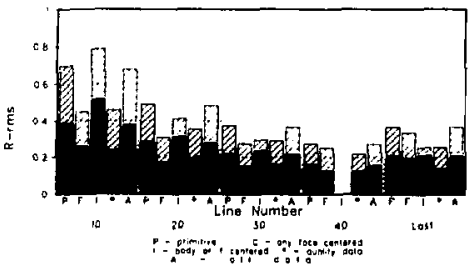


OUALITY OF POWDER DIFFRACIION STANDARDS POF Cubic Dala: Dowaltf m20

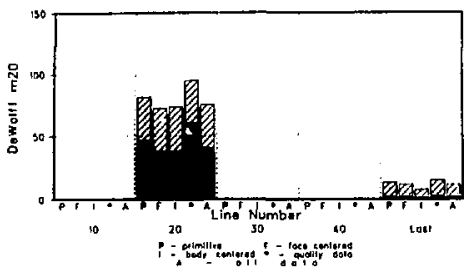

OUALITY OF POMDER DIFFRACTION STAMDLRDS Trua NBS Cubic Doto:DeWolfi ma

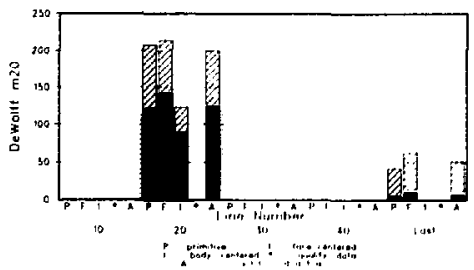

(b)
OUALITY OF PGWDER DIFFPACTIOH STAMDAROS PDF-NES Cubic Dala Dewollf M20

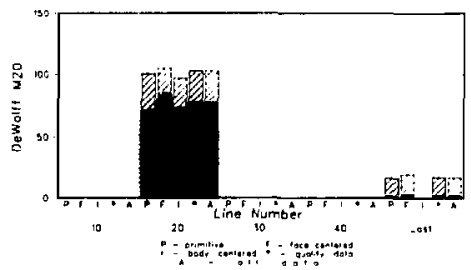

(c)
QUALITY OF POWDER DIFFRACTION STANDAROS PDF Triclinic Doto : DeWalff $\$ 20$

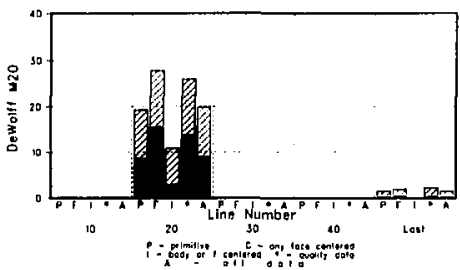

\section{b)}


QUALITY OF POWDER DIFFRACTION STANDAROS la POF Cubic coto: Dewall Mn

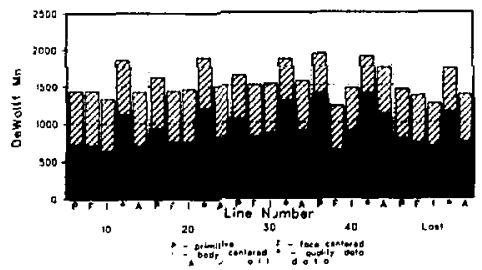

OUALITY OF FOWDER DIFFRALTION CTANDARDS True NGS Cubic Dolo DeWolft ún

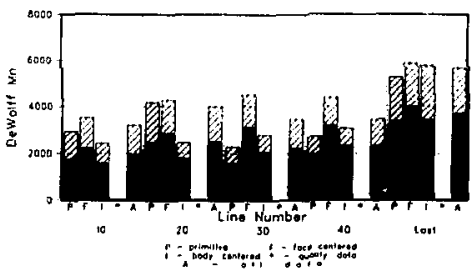

CUALITI OF POWDEF OIFFRACIION STARDAFOS (c) POF-NGS Gubic Dala: Uewolft Mn

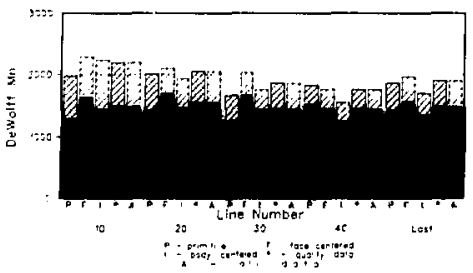

DUALITY OF POWDER DIFFRACTION STANOAROS par Triclinic Dala : OoWoll" Mn

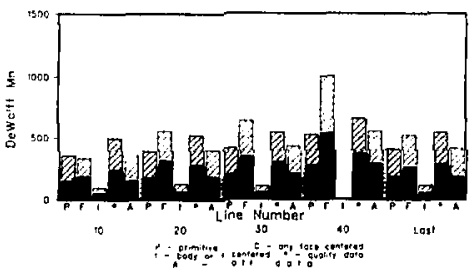

OUALITY OF POWDER DIFFRACTION STANDARDS NaS Iriclinic Data : Dewolfi Mn

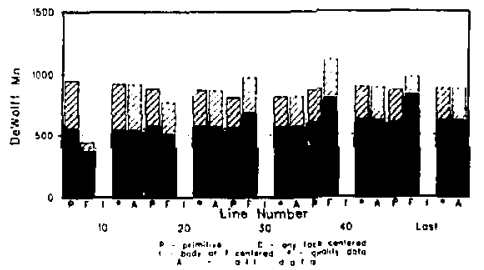

Fig. 24. Average value of $\mathrm{M}_{\mathrm{y}}$ as a function of llne number, lattlce type, and PDF quality mark. Slashed bars represent standard devintions. 
QUALITY OF PUWDER DIFTRACTION STANDARDS Ppr Cubic Dato: Dalta d 10000

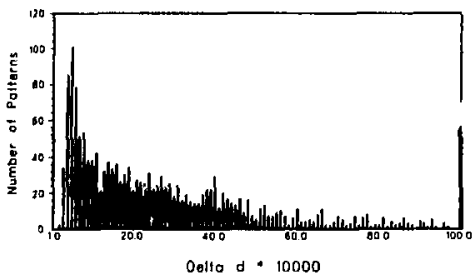

QUALITY OF POWDER DIFTraCtic. STANOAROS

True NBS Cubic Data : Delta $d+30000$

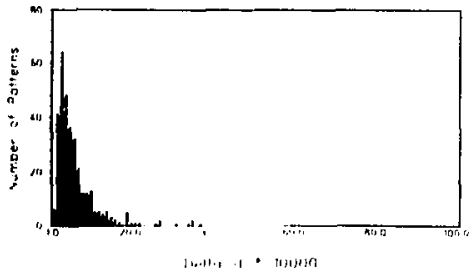

QUALITY OF POWDER DIFFRACIION STANDARDS

PDI-NBS Cubic Dratn : Delto o * 10000

(c)

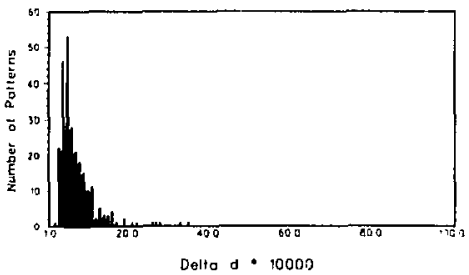

QUALITY OF POWDER DIFFRACIION STANDAROS

PDF Triclinic Data : Delta d 10000

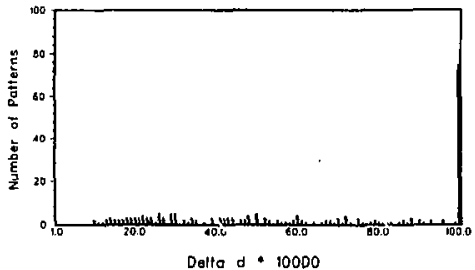

OUALITY DF POWOER DIFFRACIION STANDARIS NBS Mriclinic Bola : Deito of 10000

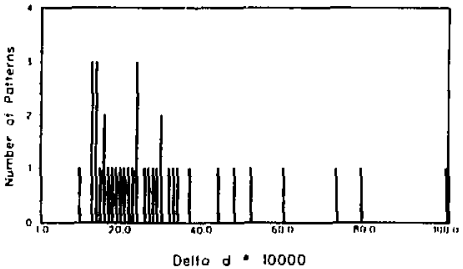

Fis. 25. Djaribution of the average value of $|\Delta d|$ for cubic and triclinic patterns. 
QUALITY OF POWDER DIFFRACTION STANDARDS

Por Cubic Doto. Uetio 2 thelo

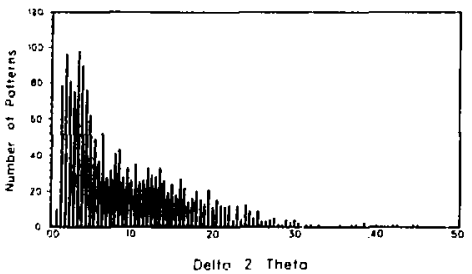

QUALITY OF POWOER DIFTRACIION STANDARDS

true NAS Cubic Doto: Dalto 2 theto

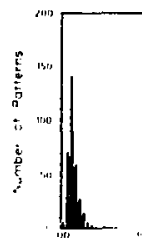

(a)

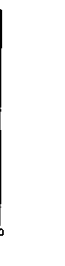

[b]

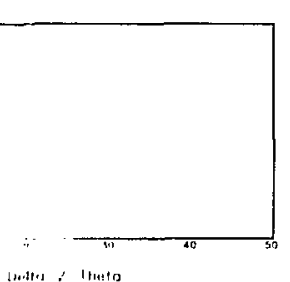

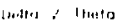

CUALITA OF POWEER DIFFPACTION STANDARDS

FOF-i:BS Cubic Dota. Usita 2 ineta

(c)

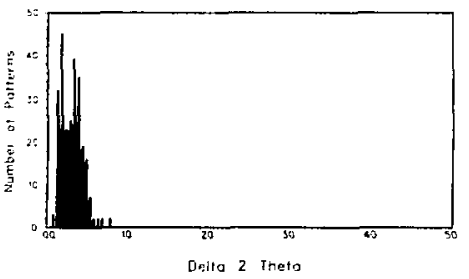

OUALITY OF POWDER DIFFRACIION STANDARDS

PDF Triclinic Dato: Delto 2 Theto

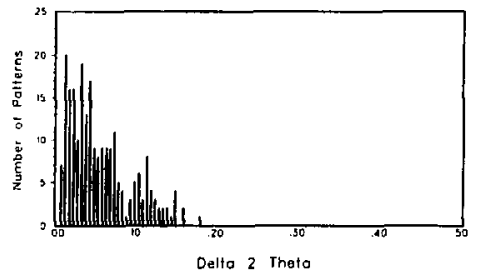

(d)
QUALITY OF POWDER DIFFACIION STANDARDS NARS trielinic Ooto : Della 2 ingta

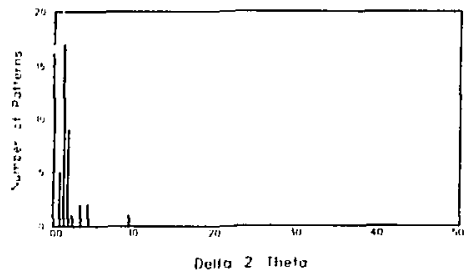

Fig. 26. Distribution of the average value of | $\mathbf{A 2 \theta}$ | for cubic and triclinic patterns. 
OUALITY OF POWDER DIFFRACIION STANDARDS

POF Cubic Dola: RMS Della 2 Thato

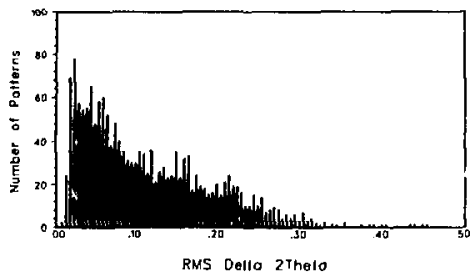

OUALITY OF POWDER DIFTRACTIOH STANDAROS

Irue NBS Cubic Dato : RMS Delto 2 Theto

(b)

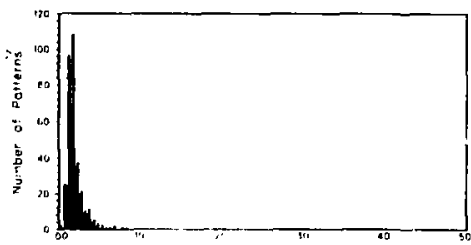

HAl, twelly theto

QUALITY OF POWDER DIFTRACTION SIAMOAPCS

(c)

PCF - NES Gubic DOto. RWS Delto zTheis

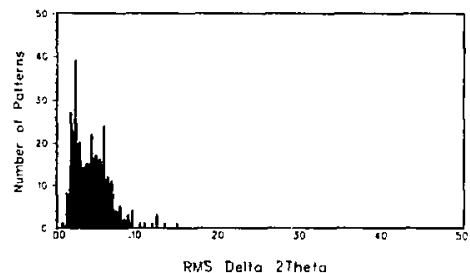

OUALITY OF POWDER DIFFRACTION STANDARDS

PDF Triclinic Dato : RMS Delto 2Thato

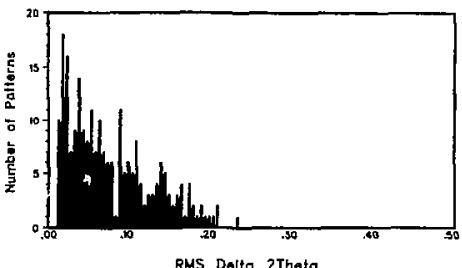

(d) OUALITY OF POWDER DIFFRACTION 5 IANDARD5 NES Triclinic Dota : RMS Oelto 2theta

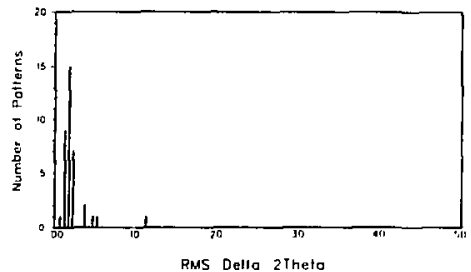

Fiz. 27. Djstribution of the average value of root mesn square | $\Delta 2 \theta \mid$ for cwbic and triclinic patterns. 
OUALITY OF POWDER DIFFRACTION STANDARDS

POF Cubic Data: Nobs / Nposs*100

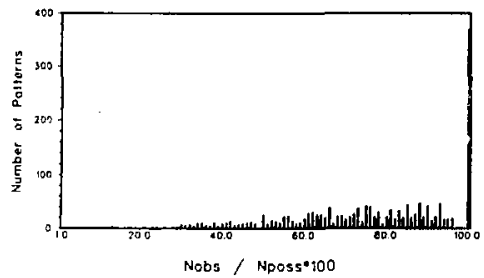

OUALITY OF POWDER DIFFRACTION STANDARDS

True NaS Cubic Dole: Nobs / Nposs*100

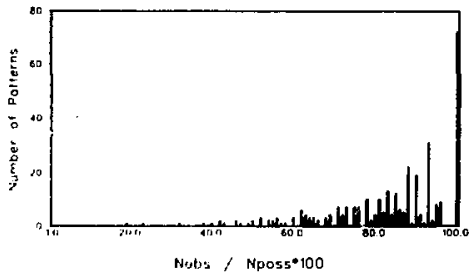

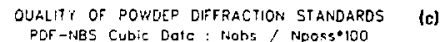

POR-INES Cubic Datc: Nohs / NpOss 100

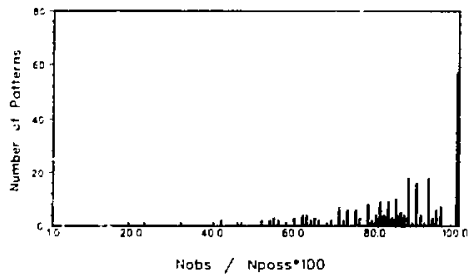

OUALITY OF POWOER OIFFRACTION STANDARDS

(d)

OUALITY OF POWDER DIFFRACTION STANDARDS

(e)

POF Triclinic Doto : l.obs / Nposs"YOO
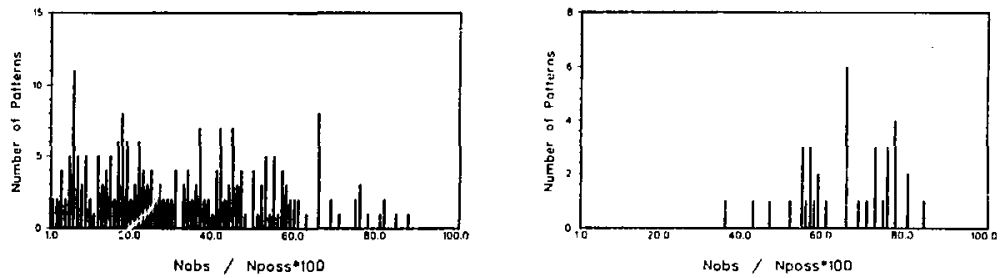

Fig. 28. Dlstribution of the aversge value of the coverage factor $N / N_{\text {pom }}$ for cubic and triclinie pattems. 
QUALITY OF POWOER OIFFRACIION STANOARDS

PDF Cubic DOTO: AV, THETA MERIT

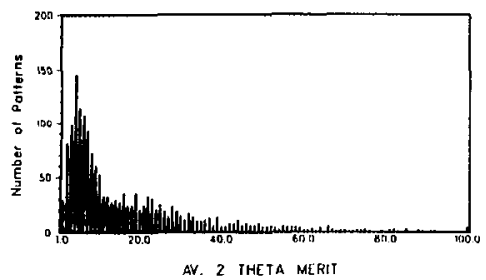

OUALITY OF POWDER DIFFRACTION STANDARDS

True NGS Cubit Dafa: AV. 2 THETA MERIT

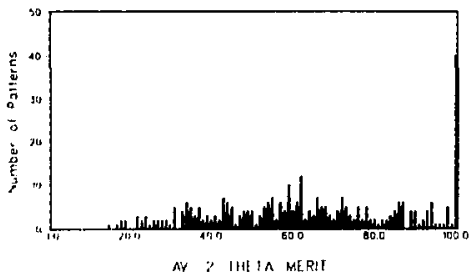

OUALIYY OF POWDER DIEFPACFICN STANDARDS

(c)

PUF-IJES Clbic DOTO. LU.? IHEIA MERIT

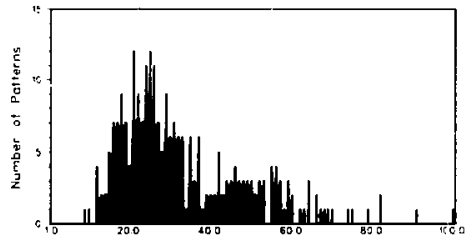

AV. 2 THETA MERIT

QUALITY OF POWDER DIFFRACTION STANOAROS PDF Trictiric Dota : AV. 2 THETA MERIT

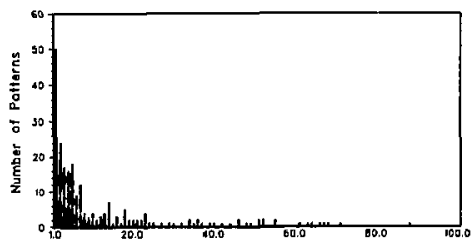

AV. 2 THETA MERIT
OUALITY OF POWDER DIFTRACIION 'IIANTHAKII. NaS Triclinic Dola : AV. Y IUl I A Mt Kil

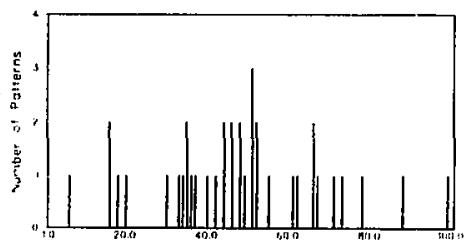

AV. 2 THETA MERIT (e)

Fig. 29, Distribution of the average value of $\mathrm{F}_{\mathrm{N}}$ for cuble and triclinic patteras. 
CUALITY OF POWDER DIFFRACTION STANDARDS

PDF Cubic Doto: RMS 2 THETA MERIT

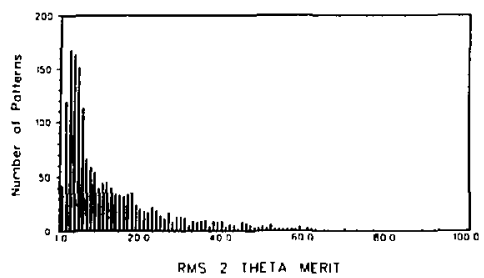

QUALIIY OF PCWOER DIFFRACTION STANDARDS

Trua NaS Cubic Dotn: RMS 2 THETA MERII

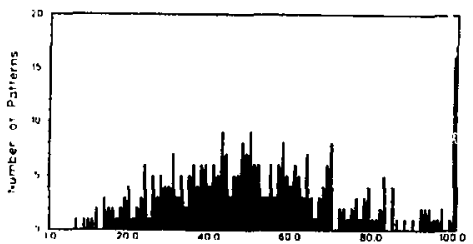

RH'S $\%$ THETA MERIT

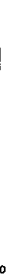

(c)

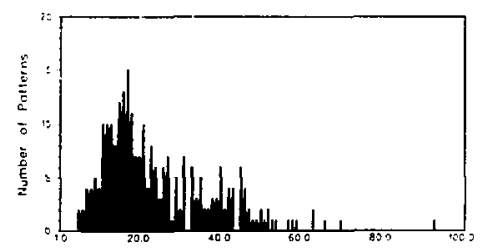

RMS 2 THETA MERIT

OUALITY OF POWDER DIFFRACTION STANDARDS

POF Triclinic DOTO: RHS 2 THETA HERIT

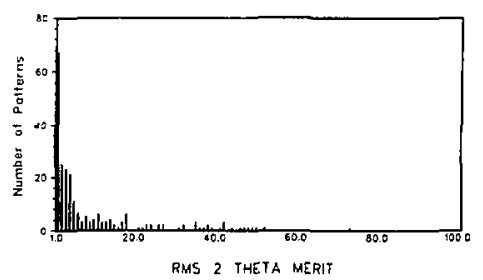

(d)
OJALITY OF POWDER DJFFRACFION SIANDARDS HBS Triclinic Datc: RHS 2 IHE TA MERI

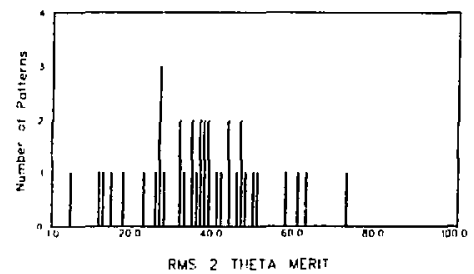

Fig. 30. Distribution of the a verage ralue of root mean square $F_{N}$ for cubic and triclinic parterns. 
QUALITY OF POWDER OIFFRACTION STANDARDS

PDF Cubic Dala : R-rms * 100

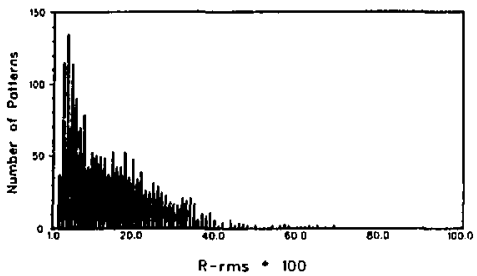

DUALITY OF POWDER DIFFRACTION STANDARDS

True NBS Cubic Oata : R-rms $* 100$

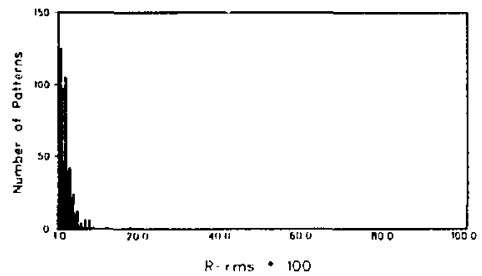

QUALITY OF POWDEP DIFFRACTION STANDAROS PDF-NBS Cudic Dato: R-rms * 100

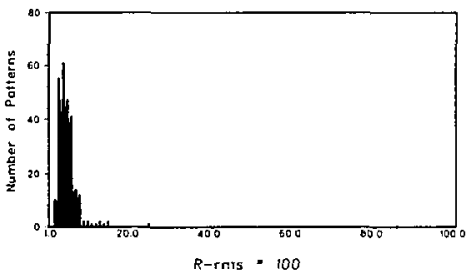

QUALITY OF POWDER DIFFRACTION STANDARDS PDF Triclinic Data : R-rms * 100

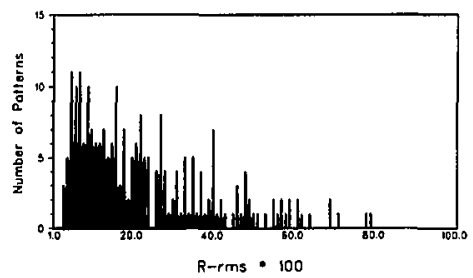

OUALITY OF POWDER DIFFRACTION STANLARIS? NeS Triclinic Doto: R-rms * 100

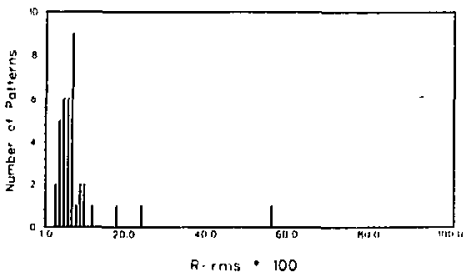

Fib. 31. Distribution of the average value of $\mathbf{R}$ for cubic and triclinic patters. 
OUALITY OF POWDEF DIFFRACIIDN STANDARDS

PDF Cubic Data : Dewalff M2O

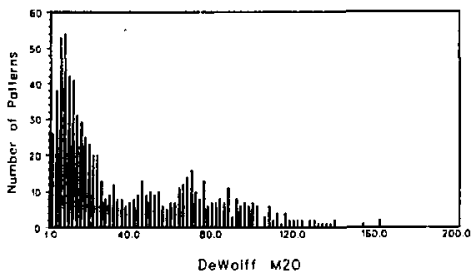

OUAIITY OF FOWDER DIFFRACTION STANDARDS True NBS Cubic Dolo: DeWolft M20

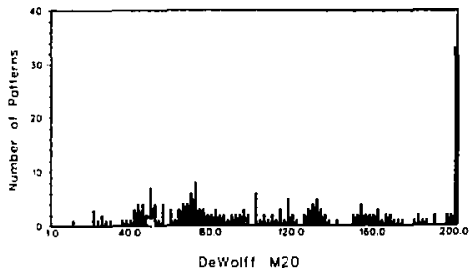

OUAL TY OF FOWDIR DIFFACTION STANUAROS FDF-NES Cutic Dato: Dewolft M2O

(c)

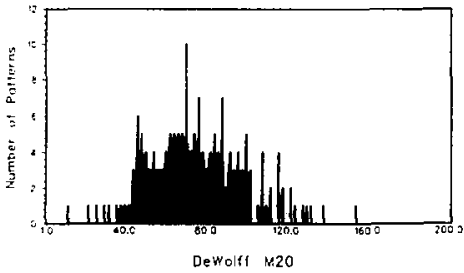

OUALITY DF POWDER DIFFRACTION STANDARDS PDF Iriclinic Data : DeWolff M2O

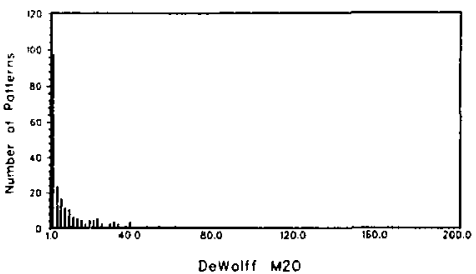

OLALITY OF POWDER DIFFRACTION STANDARDS NGS Trictinic Dato: DeWollf $M 20$

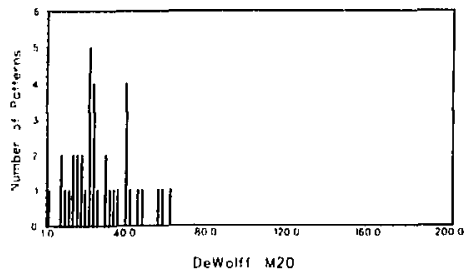

Fig. 32. Distribution of the average value of $\mathbf{M}_{30}$ for cubic and triclinic patterns, 
QUALITY OF POWOER DITFRACIION STAPDARDS

PDF Cubic Dato Dnillolf! in

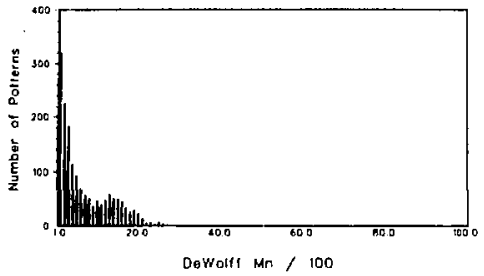

DUALIT' OF POWDER DIFFRACTION STARDARDS

Irue NeS Cubic Doto: De lolff Wn

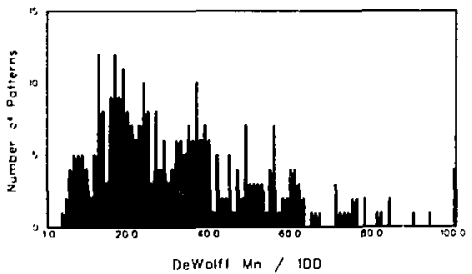

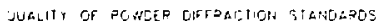

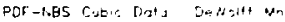

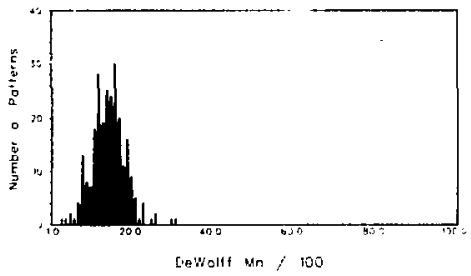

(c)
OUALITY OF POWDER DIFFRACTION STANDARDS

PDF Iriclinic Data : DeWolff Mn

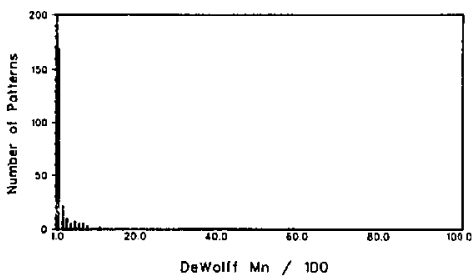


VS. A NUMEER FOR PDF CUEIC

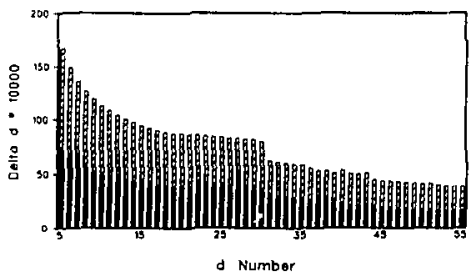

(a)

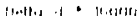

(b)

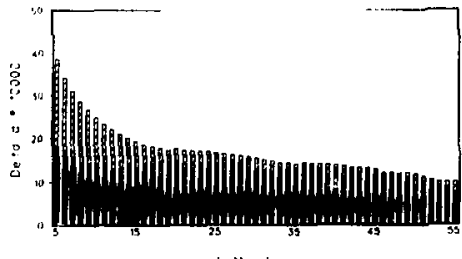

d tiumber

Delle O 10000
VS. A NGMBER FOR POT-NBS CUBD

(c)

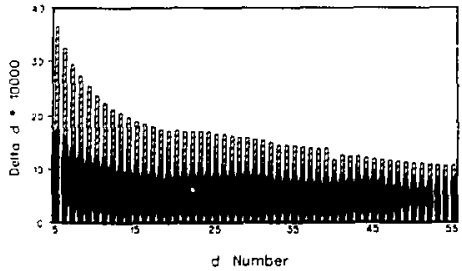

(d)

Delio o * 10000

[e]

v5. I NUMBER FOR POF TRICLINIC

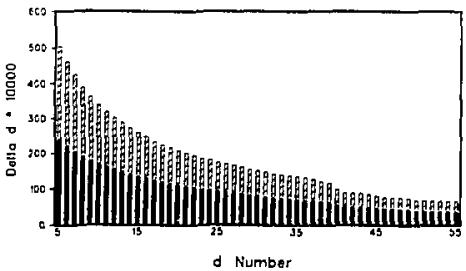

VS. O NUMBER FOH NBS TRWI HNK

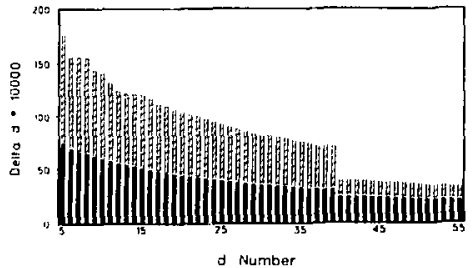

Fig. 34, I $\Delta d$ as a function of difrraction line number for cuble and triclinic patterns. Slashed bars represent standard deviations. 
Dallo 2 Theto

vS. A NUMBER FOR PDF CUBIC

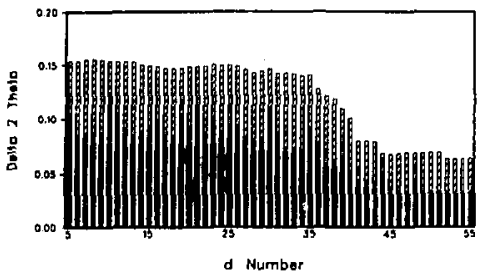

Della 2 theta v5. d MUMBER FOR TRUE NGS CUAIC

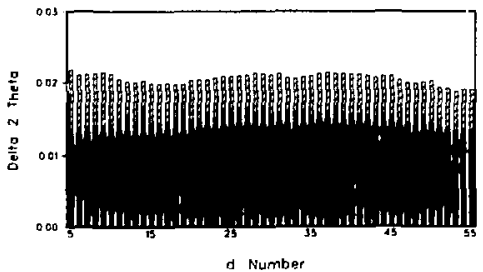

Dello 2 Theto

(c)

VS. O NUMBEP FOR POF-NES CUBIC

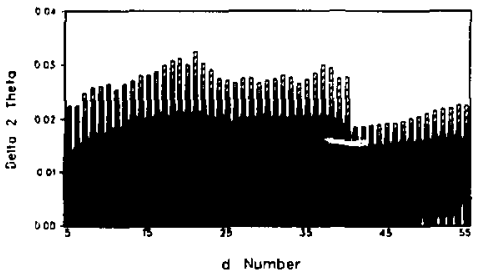

Delto 2 Theto VS. d NUMEER FOR PDF TRICLINIC

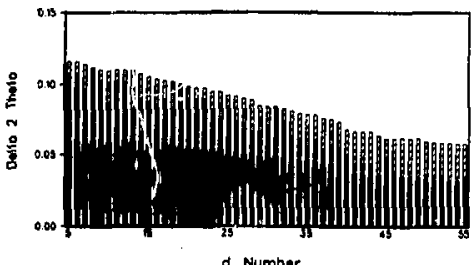

(d)

(1)

\{e\} Delta 2 Theta
YS. a NUMBER FOR NBS IRICI. INIE:

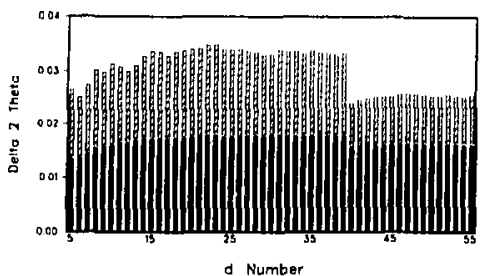

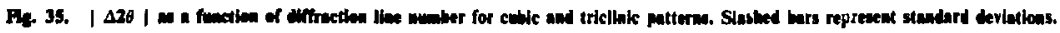


RMS Delfo 2 Theto

VS, d NUMEER FOR POF CUBIC

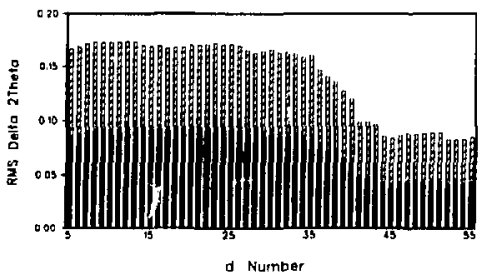

RMS Della 2 theto

YS. d NUMAER FOR IRUE NaS CUAIC

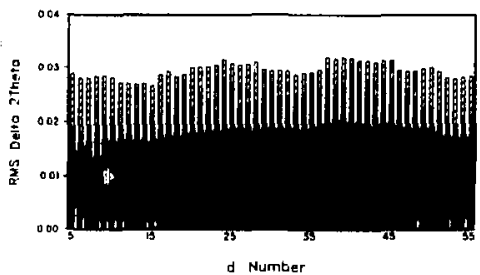

(c)

(b)

YS. d NUMEER FOP POF-NGS CUBIC 
Nobs / Nposs

vS. d NUMACR FOR POT CUBIC

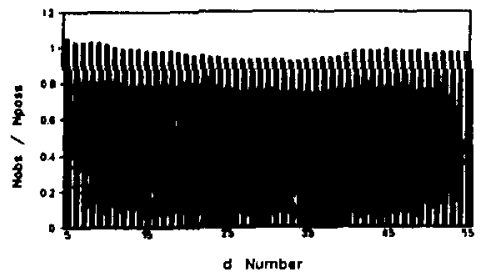

(a)

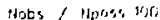

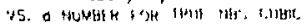

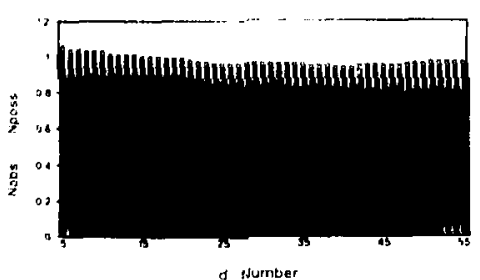

d ivurnber

(c)

VS, a hUMEER IOP POL - ThES CUEIS

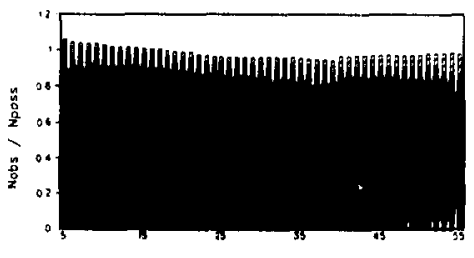

d Number

Nobs / Nposs

vS. O NUMGER TOR PDF IRICLINIC

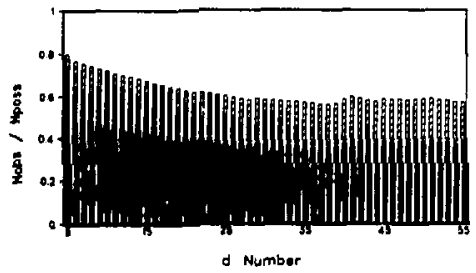

(d)

Nobs / Nposs V5. I NUWEER I OR NBS I RITI INIC,

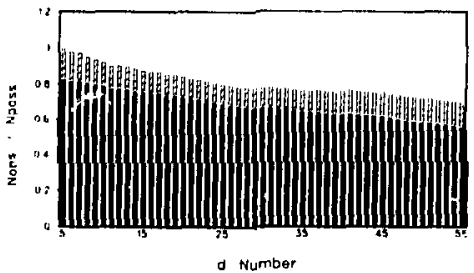

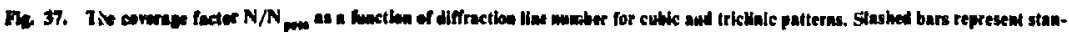

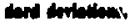


aV. 2 THETA MERIT

VS. $\triangle$ NUMBER FOR POF CUEIC

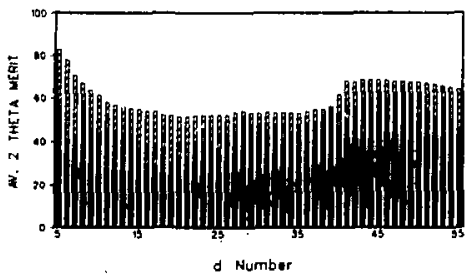

AV. 7 THI TA WERII

VS O NIJMAIH

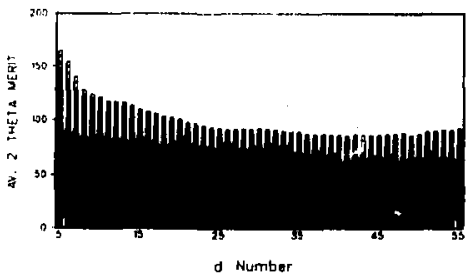

AV. 2 THETA MERIT

(c)

$\checkmark S$. A NUMETR FOR POF - HES CUEIC

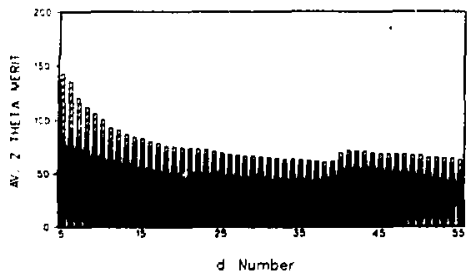

AY, 2 IHETA MERIT

V5. A NUMGER FOR PDF TRICLINIC

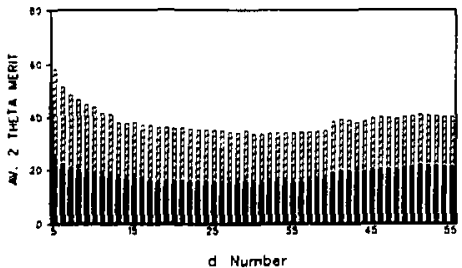

AV, 2 IHETA MLEUT VS. A NUMBER FOR NBS IRICLINIC

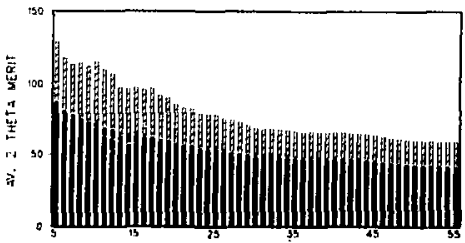

d Number

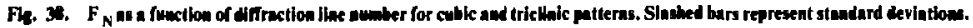


RMS 2 THETA HLH,T

VS. A NUMBER FOR POT CUBIC

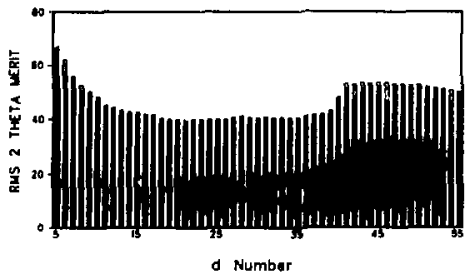

RMS 2 THETA MERIT

VS. A NUMBER FOR IRUE ABS CUAHC

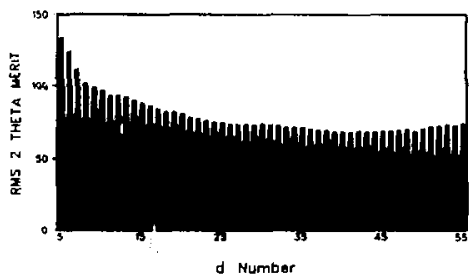

RMS 2 THETA MERIT

(c)

VS. \& NUMAER FOR POT -NBS CUEIC

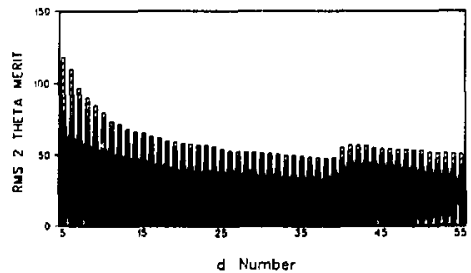

RHS 2 THETA MERIT

VS. \& NUMAER FOR NBS IAICLINIC

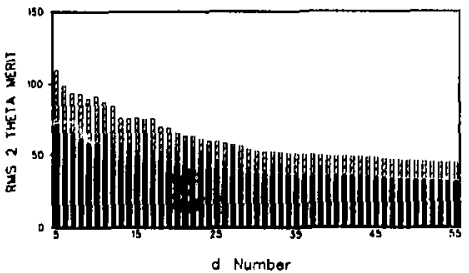

RMS 2 THETA MERIT

v5. A NUMBER FOR POF TRICLINIC

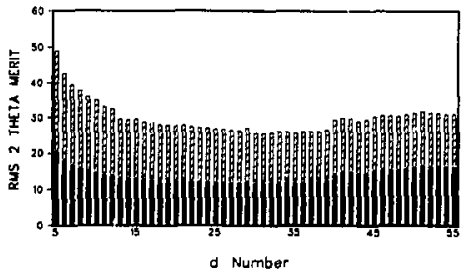

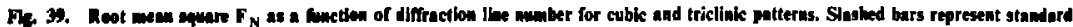
cevintiven. 
$R-r$ ms

४5. O NUMAER FOR POF CUBIC

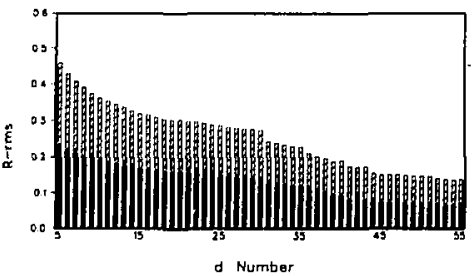

R-rms

VS. व NUMEER FOR IRUE NAS CUBIC

(b)

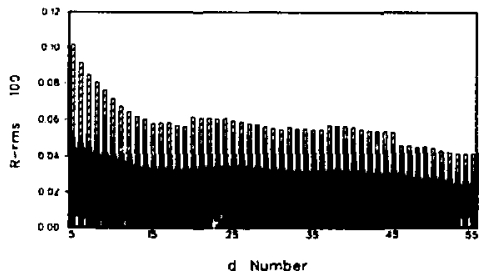

a-rms

VS. d NUMBER FOR PDF - NBS CUAIC

(c)

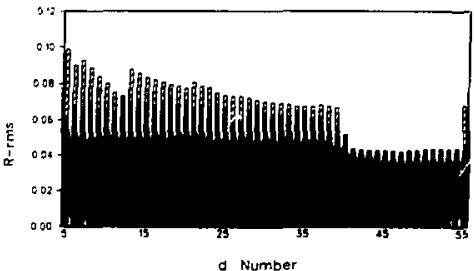

VS. O NUMBER FOR FDF TRICLINIC

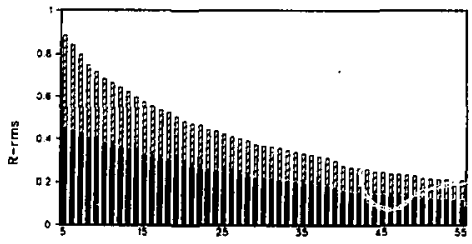

d Number (d)

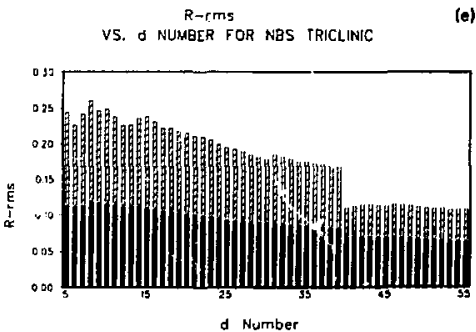

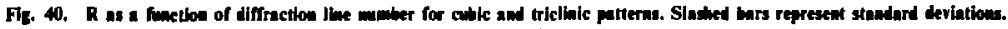


Dowollf $\mathrm{m} 2 \mathrm{O}$

VS, A MUMBER FOR PDF CUBIC

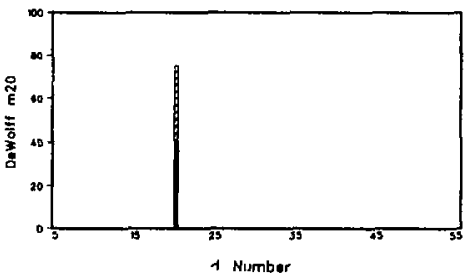

(a)
lis:W. HIP mads

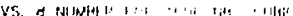

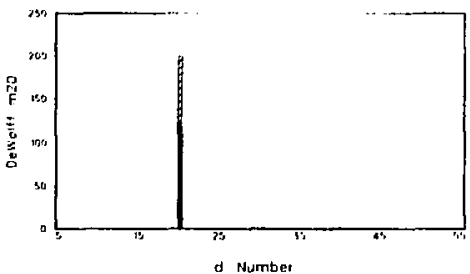

(b)

DeWolff $M 20$

(c)

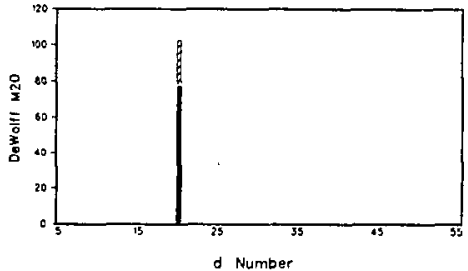

DeWoll M2O

VS, d NUMBER FOR PDF TRICLINIC

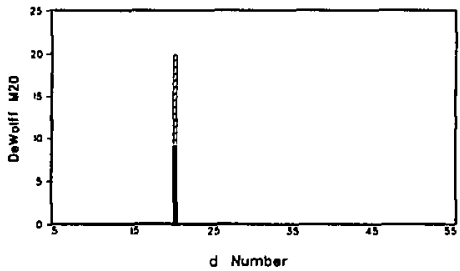

DeWal!' M2O

(e) 
Dewolft in

v5. d NUMBER FOR POT CUEIC

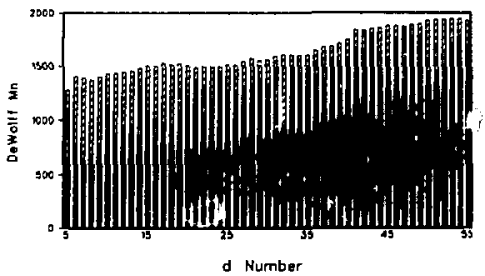

Dewalf $\mathrm{mn}$

VS. \& NUMBER FOR IRIIE NBS CUEIC

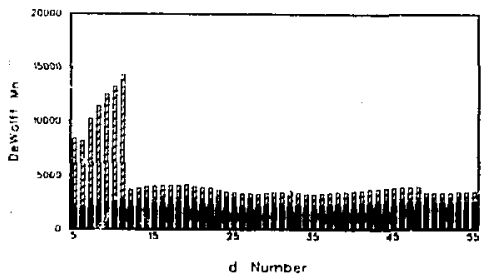

Cewo't m

(c)

VS. A NLHAER FOR DDF -NBS CUBIC

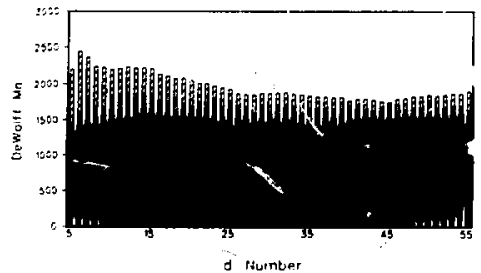

Dewalf Mn

VS. D NUMBER FOR POF TRICLINIC

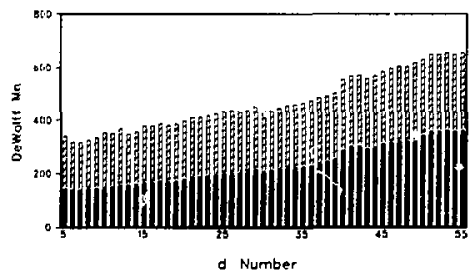

(d)
DeWolff Mn VS. D NUMEER FOR NBS IRICA.INIL

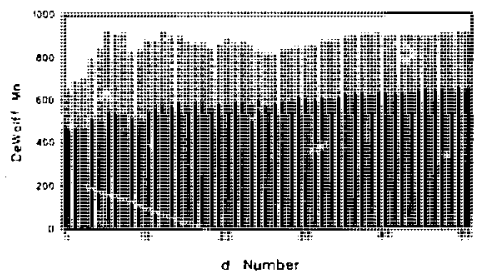

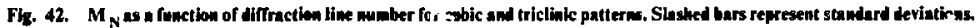


Delta $d \cdot 10000$

VS. d SALUE FOR POF CUBIC DATA

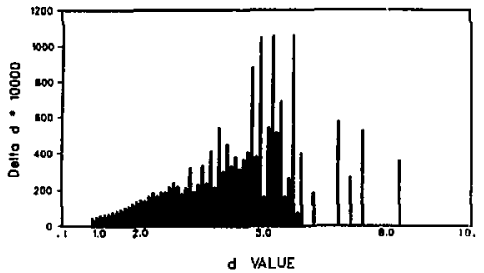

Della d 10000

(b)

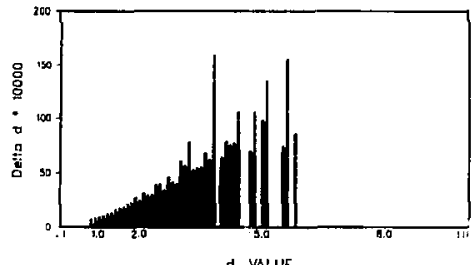

d Value

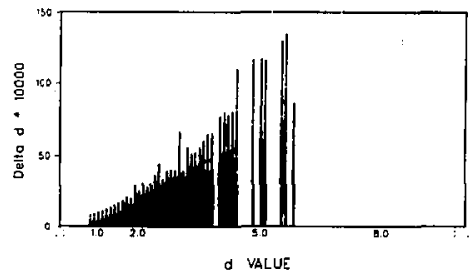

Detla $d * 10000$

vS. d VALUE FOR PDF TRICLINIC DATA

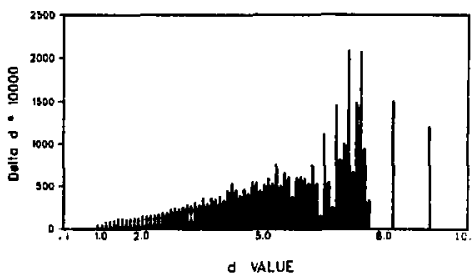

(d)
Deita d 10000

VS. I VALUE FOR NBS TRICLINIC DATA

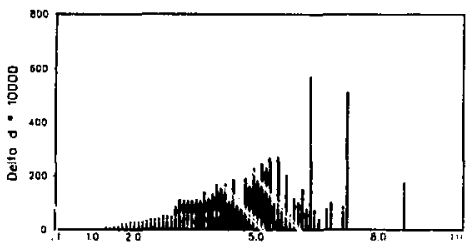

d VALUE

Fh. 43. I $\Delta d \mid a$ a functien of the value of $d$ foe cuble aw tricliac pattera. Bars above the breall represent standard deriations. 
Delto 2 theta

YS. d VALUE FOR PDF CUBIC DATA

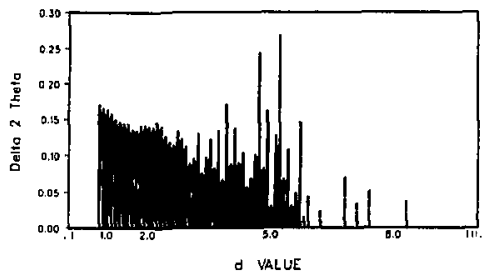

Delto 2 Theto

(b)

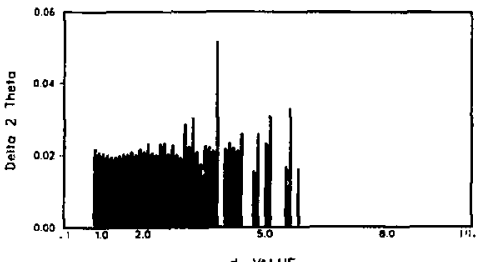

d VALUE

Della 2 Theto

(c)

VS. d VALUE FOR POF-NBS CUBIC DATA

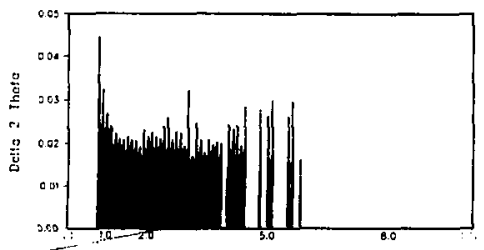

d VALUE

Delto 2 Thelo

VS. d VALUE FOR FDF TRICLINIC DATA

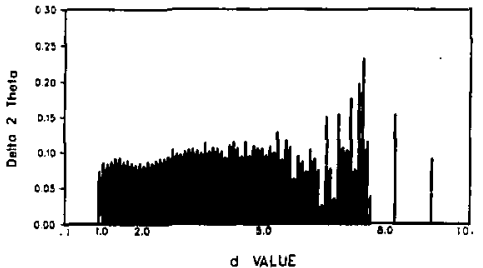

(d)
Dello 2 Theto

(e)
VS. d VALUE FOR NBS TRICLINIC DATA

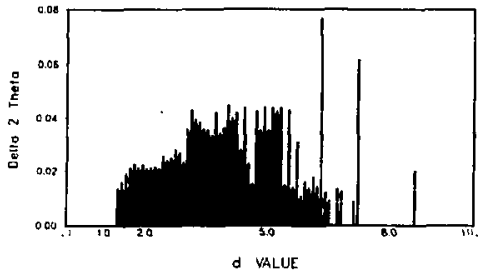

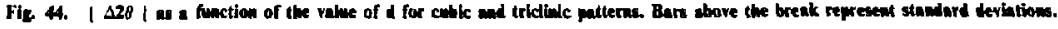


RUS Delfo 2Thoto

VS. O VALUE FOR POF CU日IC DATA

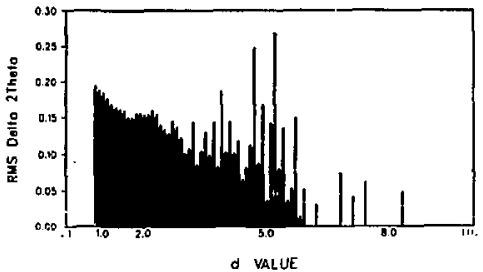

RMS Delta 2Theta

(b)

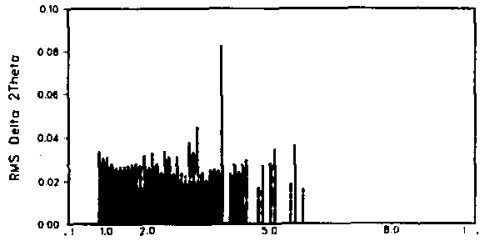

d VAIUE

VS Delio 2 Theto

(c)

VS. d VALUE OR POF-NBS CUEIC DATA

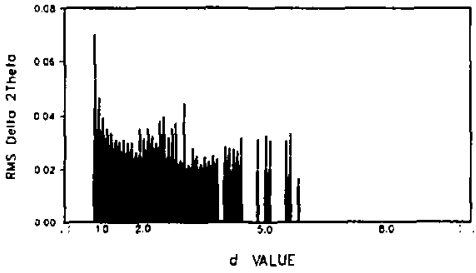

RMS Della 2 Thefo

YS. d VALUE FOR PDF TRICLINIC DATA

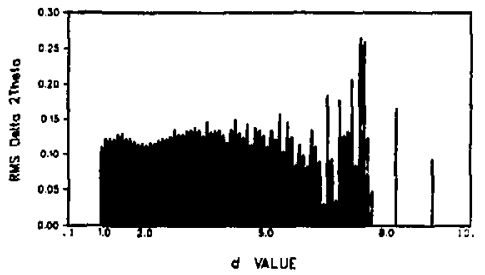

RMS Dello 2 Thato

YS. d VALUE FOR NBS IRICI INIC DATA

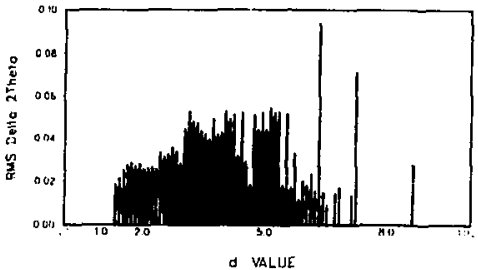

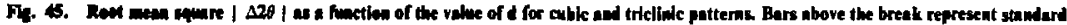
ievietion. 
Nobs / Nposs

VS. d VALUE FOR PDF CUBIC DATA

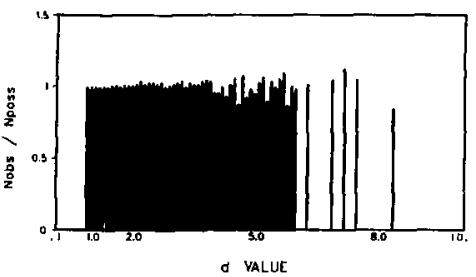

(a)

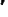

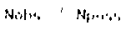

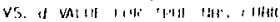

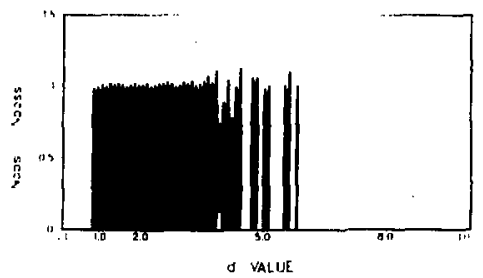

(c)

Nibs / Nposs

VS. d VALUE FOR POF-NBS CUBIC DATA

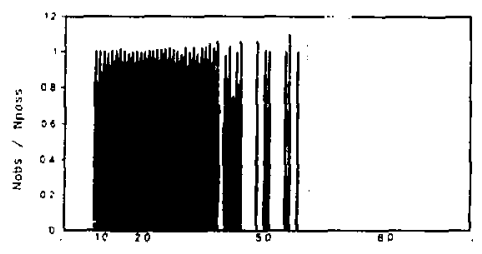

a VALUE

Nobs / Npos:

VS. d VALUE FOR PDF TRICLINIC DATA

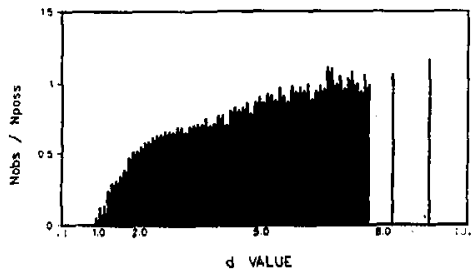

Nobs / Hposs

(d)

VS. I YALUE FOR NGS TRICLINIC DATA

(e)

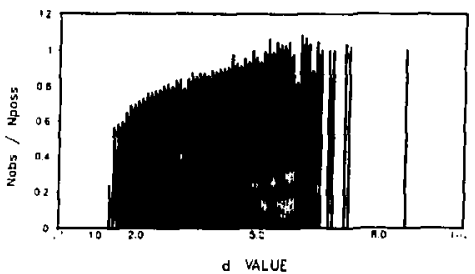

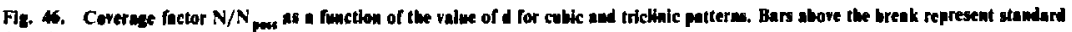
ieviatian. 
AV. 2 THETA MERIT

VS. O VALUE FOR POF CUBIC DATA

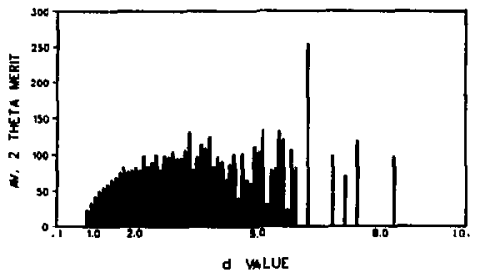

\{a\}
aV 2 IIt IA MF kil

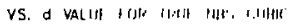

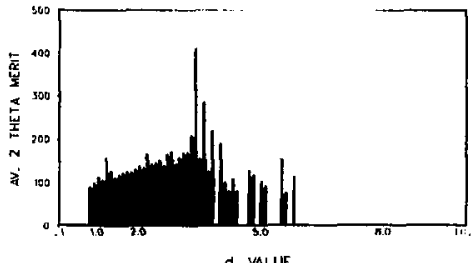

AV. 2 THETA MERIT

(c)

VS. VALUE FOR POF-NES CUEIC DATA

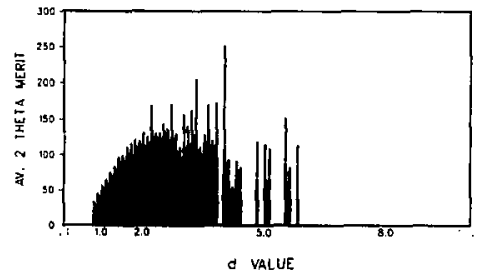

AV. 2 THETA MEFIT

VS. d VALUE FOR POF TRICLINIC DATA

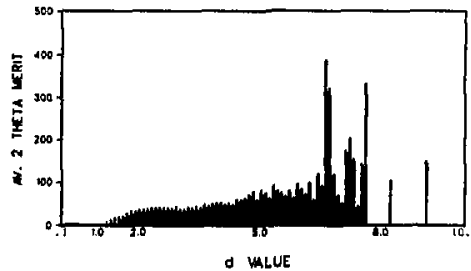

(d)
AV, 2 THETA MERIT

V5. d VALUE FOR NES JRICLINIC DAIA

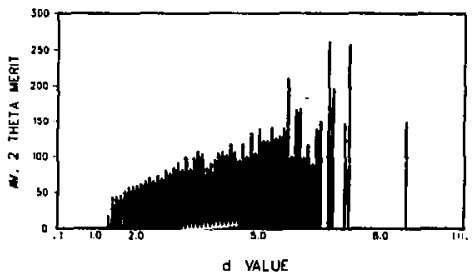

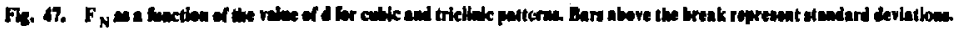


RUS 2 THETA MERIT

VS. d VALUE FOR PDF CUEIC DATA

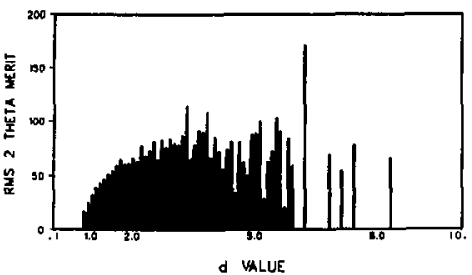

RUS 2 IHFTA UFRII

VS. D VALIJE IOR IRIII NES COSBIC

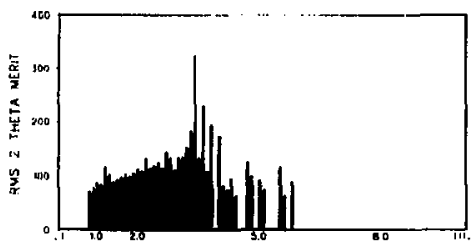

a VALUE

(b)

RNS 2 THETA MERIT

(c)

VS. I VALUE FOR PDF - NBS CUBIC DATA

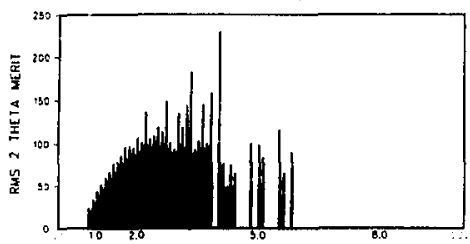

d VALUE

RMS 2 THETA MERII

VS, d VALUE FOR PDF TRICLINIC DATA

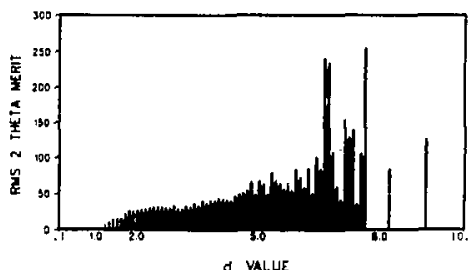

RHS 2 THETA MERIT

VS. \& VALUE FOR NBS TRICLINIC DATA

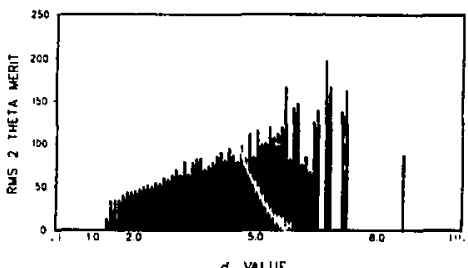

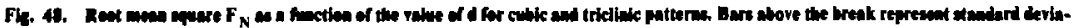
tion. 
$A-r$ ms

VS. \& VALUE FOR POF CUBIC DATA

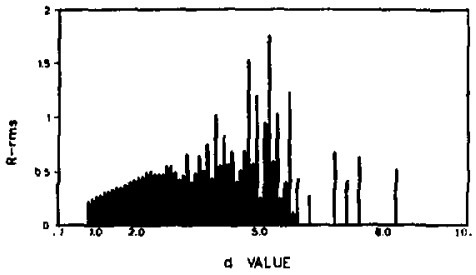

(a)
R-rms:

VS. d Wheth IOW IHIII HH, CHHIC:

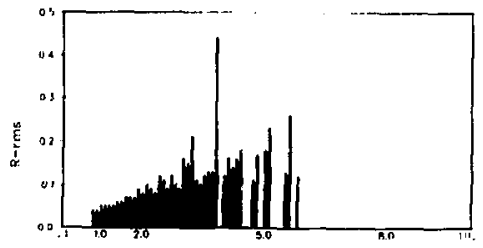

d VALUE

VS, d VALUE FOP PDF-NES CUBIC DATA

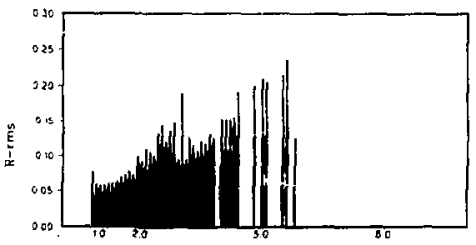

d VALUE

$\mathrm{R}-\mathrm{rms}$

V5. O YALUE FOR PDF TRICLINIC DATA

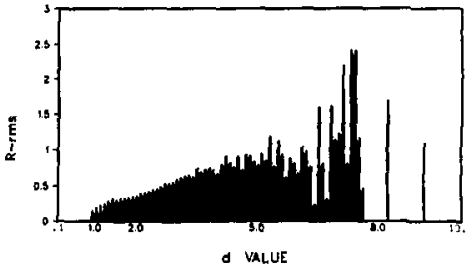

$\mathrm{R}-\mathrm{rms}+10^{r}$

VS. d VALUE FOR NAS IRICI.INIC UAIA

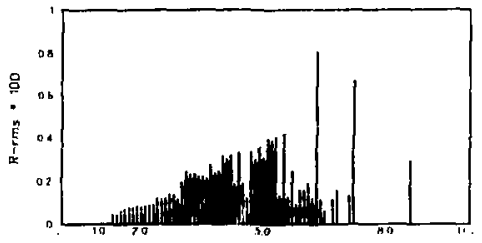

d VALUE

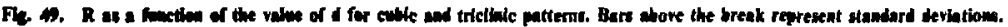


V5. d VALUE FOR PDF CUBIC DATA

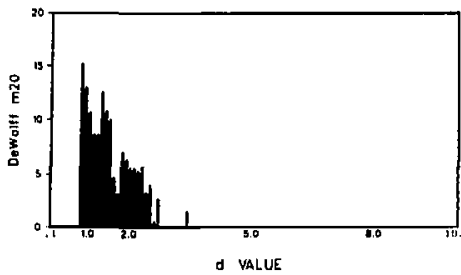

VS. C VALLE FOR TRIL' NUS CUBIC

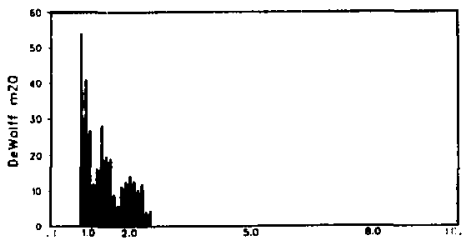

a VALUE

Dewolfl M2O

vS. d VALUE FOR POF-NGS CUGIC DATA

(c)

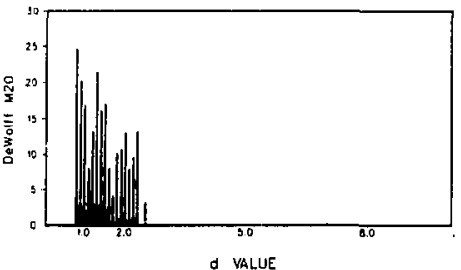

DeWolf N2O

VS. d VALUE FOR POF TRICLINIC DATA

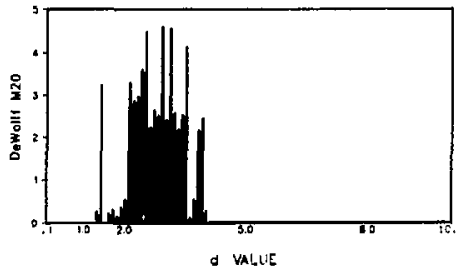

(d)

Dewalf W20 VS, d VALUE FOR NBS IRICLINIC DATA

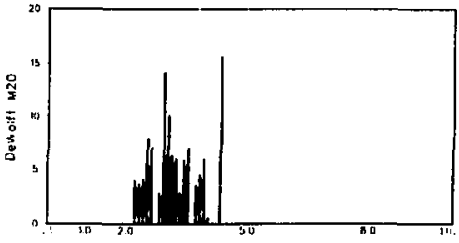

d VALUE

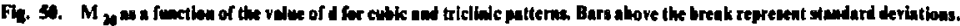


Dawalli Mn

VS. A VALUE FOR PDF CUEIC OATA

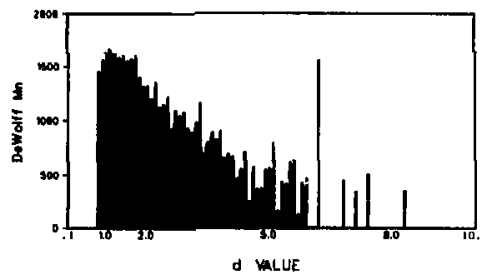

Dewolff un

(b)

VS, d VALUE FOR TRUE NOS CUEIC

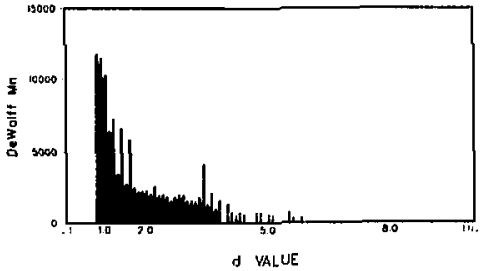

(c)

VS. I VALUE TOR POF-NBS CUBIC DATA

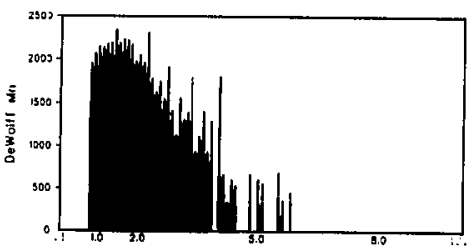

d YALUE

Dowolif Wn

VS. D VALUE FOR POF TRICLINIC DATA

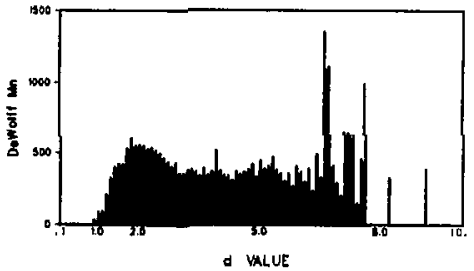

DeWollt $\mathrm{Mn}$

(e) VS. $d$ VALUE FOR NES TRICIINIC DATA

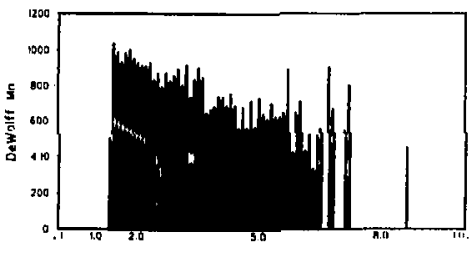

d YALUE

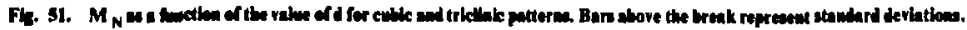




\section{REFERENCES}

1. JCPDS International Centre for Powder Diffraction Standards, 1601 Park Lane, Swarthmore, PA.

2. L. K. FREVEL, "Chemical Analysis by Powder diffraction," Ind. and Eng. Chem. and Ed. 16, 209-218 (1944).

3. M. C. Nichols, Graphical Representations of Selected Functions of Interplaner Spacings for 5184 Inorganic $x$-ray Powder Diffraction Patterns, Lawrence Livermore Laboratory, Rept. UCRL-50115 (1966).

4. Peter Keller, CHARTIT: A Computer Program That Constructs Bar Graphs in Color, Lawrence Livermore Laboratory, Rept., UCRL-52310 (1977).

5. P. M. de Wolff, "A Simplified Criterion for the Reliability of Powder Pattern Indexing," J. Appl. Cryst. 1, 108-113 (1968).

6. W. Nowacki, "Crystal Data Systematic Tables," American Crystallographic Association Monograph 6 (1967).

7. A. D. Mighell, "Symmetry and Reduced Cells" in Proc. of American Crystallographic Association Meeting, Asilomar, Calif., 1977, Rept. JN3.

8. "Standard X-Ray Diffraction Powder Patterns," United States Department of Commerce, National Bureau of Standards, Circular 539, Vols. 1-10 (1953-1960), Monographs 25, Sections 1-14, (1962-1977).

9. G. S. Smith and R. L. Snyder, " $F_{\mathrm{N}}$ : A Criterion for Rating Powder Diffraction Patterns and Evaluating the Reliability," of Powder Pattern Indexing J. Appl. Cryst., to be published. 